\title{
The study of equatorial plasma bubble during January to April 2012 over Kolhapur (India)
}

\author{
Parashram T. Patil ${ }^{1}$, Rupesh N. Ghodpage ${ }^{1,{ }^{\star}}$, Alok K. Taori ${ }^{2,3}$, Rohit P. Patil ${ }^{4}$,
} Subramanian Gurubaran ${ }^{5}$, Suraj N. Nikte ${ }^{6}$, Dada P. Nade ${ }^{7}$, Ashok K. Sharma ${ }^{8}$, Sridhar Banola ${ }^{5}$, V. Lakshmi Narayanan ${ }^{9}$, Devendraa Siingh ${ }^{10}$

${ }^{1}$ MF Radar, Indian Institute of Geomagnetism, Shivaji University Campus, Kolhapur, Maharashtra, India

${ }^{2}$ National Atmospheric Research Laboratory, Pakala Mandal, Gadanki, Andhra Pradesh, India

${ }^{3}$ National Remote Sensing Center (NRSC), Hyderabad, India

${ }^{4}$ D.Y. Patil Engineering College, Kolhapur, Maharashtra, India

${ }^{5}$ Indian Institute of Geomagnetism, Navi Mumbai, Maharashtra, India

${ }^{6}$ Vishveshwarya Technical Campus, Department of Basic Sciences and Humanities, Patgaon, Miraj, Maharashtra, India

${ }^{7}$ Sanjay Ghodawat Group of Institutions, Department of Physics, Atigre, Kolhapur, Maharashtra, India

${ }^{8}$ Shivaji University, Department of Physics, Kolhapur, Maharashtra, India

${ }^{9}$ Indian Institute of Science Education and Research Mohali, Mohali, Punjab, India

${ }^{10}$ Indian Institute of Tropical Meteorology, Pune, Maharashtra, India

\section{Article history}

Received September 10, 2015; accepted April 18, 2016.

Subject classification:

Equatorial plasma bubbles, Zonal wind velocity, ESF, All-sky imager, Airglow.

\section{ABSTRACT}

Over 53 nights of all sky airglow imager data collected during JanuaryApril 2012 from the low latitude station Kolhapur $\left(16.68^{\circ} \mathrm{N}, 74.26^{\circ} \mathrm{E}\right.$; $10.6^{\circ} \mathrm{N}$ dip latitude) have been analyzed to study the F-region dynamics through the imaging of OI $630 \mathrm{~nm}$ emission line. The observed night airglow data were supported by the ionosonde measurements from Tirunelveli $\left(8.7^{\circ} \mathrm{N}, 77.8^{\circ} \mathrm{E} ; 0.51^{\circ} \mathrm{N}\right.$ dip latitude). Well defined magnetic field aligned depletions were observed during the observation period. Out of 53 nights, 40 nights exhibited the occurrence of north-south aligned equatorial plasma bubbles. These plasma bubbles were found moving towards east with drift speed in range between 70 to $200 \mathrm{~m} \mathrm{~s}^{-1}$. We have analyzed the zonal drift velocity variation and relation of bubble occurrence with the base height of the ionosphere together with the effects of the geomagnetic Ap and solar flux $F_{10.7} \mathrm{~cm}$ index in its first appearance.

\section{Introduction}

The equatorial spread $\mathrm{F}$ (ESF) irregularities occurring on the night side of the equatorial and low latitude ionosphere have been studied for several decades using a variety of instruments [Kelley 1989]. The optical signatures of ESF which are termed as equatorial plasma bubbles (EPBs)/ depletion, were first discovered by in-situ satellite measurements [Hanson and Sanatani 1973, McClure et al. 1977] and later confirmed by rocket experiments [Kelly et al. 1976, Morse et al. 1977]. It is a phenomenon that covers a wide range of scale sizes which have been attributed to the irregularities in the plasma densities. The generation of these irregularities is a complicated process due to the fact that it is an outcome of the interplay between several processes such as pre-reversal enhancement, E-region conductivity and symmetry or asymmetry of the equatorial ionization anomaly and also a suitable seed perturbation [Kelley 1989]. According to the present understanding, the Rayleigh-Taylor instability is believed to be that the fundamental process governing the formation of narrow channels of deep plasma bite-out in the nighttime equatorial ionosphere namely, equatorial plasma bubble (EPB) and is also responsible for the generation of ESF and scintillation [Kelly et al. 1976, 2002].

Based on numerous studies using data from space borne and ground based techniques, it is widely accepted that the OI $630 \mathrm{~nm}$ emissions are generated at low latitude F-region heights $(\sim 250-300 \mathrm{~km})$. The OI $630 \mathrm{~nm}$ emission is closely related to the F-region electron density [Tinsley et al. 1973, Sahai et al. 1981, Link and Cogger 1989, Ghodpage et al. 2012] by the following mechanism; 


$$
\begin{aligned}
& \mathrm{O}^{+}+\mathrm{O}_{2} \rightarrow \mathrm{O}_{2}^{+}+\mathrm{O} \\
& \mathrm{O}_{2}^{+}+\mathrm{e}^{-} \rightarrow \mathrm{O}\left({ }^{1} \mathrm{D}\right)+\mathrm{O} \\
& \mathrm{O}\left({ }^{1} \mathrm{D}\right) \rightarrow \mathrm{O}\left({ }^{3} \mathrm{P}\right)+\mathrm{h}(630 \mathrm{~nm})
\end{aligned}
$$

because reaction of Equation (1) dominates the whole process, the production of the OI $630 \mathrm{~nm}$ emission is proportional to the molecular oxygen density $\left[\mathrm{O}_{2}\right]$ and the oxygen ion density $\left[\mathrm{O}^{+}\right]$. The oxygen ion density $\left[\mathrm{O}^{+}\right]$is almost equal to the electron density $\mathrm{Ne}$ in the $\mathrm{F}-$ layer. Thus, the OI $630 \mathrm{~nm}$ emission is a sensitive indicator of the electron density in the bottom side of the F-layer. Many optical airglow studies have been performed in recent years to image the equatorial plasma bubbles [Garcia et al. 1997, Mendillo et al. 1997, Kelley et al. 2002, Martinis et al. 2003, Mukherjee 2003, Pimenta et al. 2003a, Sahai et al. 2004, Mukherjee and Shetty 2008, Narayanan et al. 2012, Sharma et al. 2013, Taori et al. 2013, Sharma et al. 2014, Taori and Sindhya 2014]. The EPBs are generally aligned along the magnetic field lines, owing to the much greater conductivity in the magnetic field direction compared with the perpendicular conductivity. As these bubbles move buoyantly upward with respect to the ambient plasma in the equatorial region, their bottom side feet migrates away from the equator, reaching dip latitudes [Mendillo et al. 1997] of over $\pm 15^{\circ}$. At the boundaries and within the bubbles, small-scale size irregularities are generally produced which give rise to strong very high frequency (VHF) nighttime scintillations in the satellite beacon signals [Mukherjee 2003]. The plasma zonal drift velocities associated with the bubbles constitute an important parameter for thermospheric studies. EPBs usually drift eastward in the equatorial ionosphere and are often tilted to the west of the magnetic meridian. In the Indian region the occurrence of $\mathrm{F}$ region irregularities has been studied by several researchers using VHF band scintillations [Das Gupta et al. 1981, Chakraborty et al. 1999], total electron content [Dashora et al. 2012], VHF radar [Rao et al. 1997, Patra et al. 2013] and airglow studies [Mukherjee 2003, Ghodpage et al. 2012, Narayanan et al. 2012, Siingh et al. 2012, Taori et al. 2013, Ghodpage et al. 2014, Sharma et al. 2014, Ghodpage et al. 2015].

The occurrence of $\mathrm{F}$ region irregularities has been studied by researchers using ionosonde data [Chandra et al. 2003, Shi et al. 2011]. Four types of ESF observed in inosonde data, range spred $\mathrm{F}$ (RSF), strong range $\mathrm{SF}$ (SSF), frequency SF (FSF), and mixed SF (MSF) [Piggott and Rawer 1972]. However another type of RSF, which we call strong range SF (SSF) and FSF are frequently observed over Tirunelveli as noted in our obseravations. The SSF is characterized by extended range spread on $\mathrm{F}$ layer echo traces that significantly extend beyond the local foF $F_{2}$ value, while the local $\mathrm{foF}_{2}$ is estimated at $\sim 6 \mathrm{MHz}$. Such conditions seen last for more than $\sim 2 \mathrm{~h}$. Some time we also observed SSF spred F.

During the plasma bubble growth, the plasma velocity within a bubble is different from the ambient background plasma drift velocity. However, fully developed bubbles move together with the background plasma drift as "fossilized" structures until the morning sunlight refills the depleted flux tubes due to enhanced ionization [Makela et al. 2004]. The equatorial F region plasma depletion zonal velocity has proven to be an important parameter for the prediction of the occurrence of scintillations of satellite to ground RF signals [Valladares et al. 2002]. The plasma zonal drift velocity was first reported by Woodman [1972] by using radar measurements at Jicamarca, Peru $\left(12^{\circ} \mathrm{S}, 76.9^{\circ} \mathrm{W}\right)$. Since then, extensive studies of plasma bubble zonal velocities have been conducted using a variety of techniques including ground-based radar, thermospheric airglow, and satellite measurements [Fejer et al. 1991, de Paula et al. 2002, Pimenta et al. 2003ab, Sagawa et al. 2003, Arruda et al. 2006]. All of these studies show that usually the EPBs propagate eastward during the nighttime under quiet magnetic conditions [Taylor et al. 1997, Abdu et al. 2009]. However, in recent times, there are reports suggesting that not only geomgnetically disturbed, but also during quiet time conditions, EPBs can drift westward [Otsuka et al. 2012].

Earlier investigation of Sharma et al. [2013] reported the occurrence characteristics and seasonal variability of EPBs based on three years (2010-2012) data and found that occurrences of EPBs were maximum during the months October to April and minimizes on the month of May. Aim of the present study is to obtain the EPB charactieristics during January-April 2012 (maximum occurrence months) in terms of their (i) duration of occurrence or display in optical data, (ii) initial (first) appearance time of EPB in optical data and its relation with the ESF occurrence in ionosonde data over an equatorial station, (iii) variability in the EPB zonal drift velocity and (iv) solar activity impact on the EPB velocity. To undertake the above investigations we avoid the data for multiple years (due to uneven statistics of cloud occurrences from one year to the other). As the EPB observation time has seasonal preferences with summer time ESF occurring post midnight [Li et al. 2011], we have not included the summertime data. For these reasons we have restricted our analysis for January-April 2012. Further, as most reports indicate that pre midnight drift velocities have a positive correlation with solar activity [Pimenta et al. 2001, Fejer et al. 2005], we investigate the possibility of such effect in short duration data of EPB drift velocities and the observed occurrence time stretches of EPBs. Further, the observed zonal plasma bubble drift speeds are compared 
with the thermospheric zonal neutral wind speed obtained from the horizontal wind model 07 (HWM07).

\section{Instrumentations}

\subsection{All sky airglow imager}

Regular observations of night airglow OI $630 \mathrm{~nm}$, $\mathrm{OI} 557.7 \mathrm{~nm}$ and $\mathrm{OH}$ emission were carried out by using all sky airglow imager (ASAI) and multispectral photometer at lower latitude station Kolhapur on moonless clear-sky nights. Six thin film coated interference filters are used in the filter wheel to allow the transmission of OI $630 \mathrm{~nm}$, OI $557.7 \mathrm{~nm}, \mathrm{OH} 840 \mathrm{~nm}, \mathrm{OH} 846 \mathrm{~nm}$, and $\mathrm{OH}$ Meinel bands at $720-910 \mathrm{~nm}$ and the background sky noise at $857 \mathrm{~nm}$. The OI $630 \mathrm{~nm}$ data were obtained from dusk-to-dawn during moonless period using integration time of $120,120,06,06,90$ and 10 s respectively. The typical band width of the filters except the $\mathrm{OH}$ Meinel bands are $2 \mathrm{~nm}$ approximately. A high-resolution $(1024 \times 1024$ pixels $)$ charge-coupled device $(C C D)$ chip captures the image of the sky with nearly $180^{\circ}$ field of view (FOV). Before the operation, dark counts are reduced by thermoelectrically cooling of CCD to $-80^{\circ} \mathrm{C}$. The filter wheel and camera shutter are controlled by a computer. More detail of experimental setup has been described in Ghodpage et al. [2014].

\subsection{Canadian avanced digital ionosonde}

To investigate the ionospheric conditions during the observation period, we have used the ionosonde data at Tirunelveli $\left(8.71^{\circ} \mathrm{N}, 77.81^{\circ} \mathrm{E} ; 0.51^{\circ} \mathrm{N}\right.$ dip latitude). The Canadian advanced digital ionosonde consists of a transmitter, four receivers, and two sets of the antenna system. The transmitter is a delta dipole antenna, and the receiver antenna array consists of four dipoles arranged in the form of a square [Grant et al. 1995]. The transmitter unit is capable of operating in the frequency range of $1-30 \mathrm{MHz}$ with a peak power of $600 \mathrm{~W}$. The pulse length is $40 \mu \mathrm{s}$ and samples are taken at every $20 \mu \mathrm{s}$ proving a height resolution of $6 \mathrm{~km}$. For the present in-

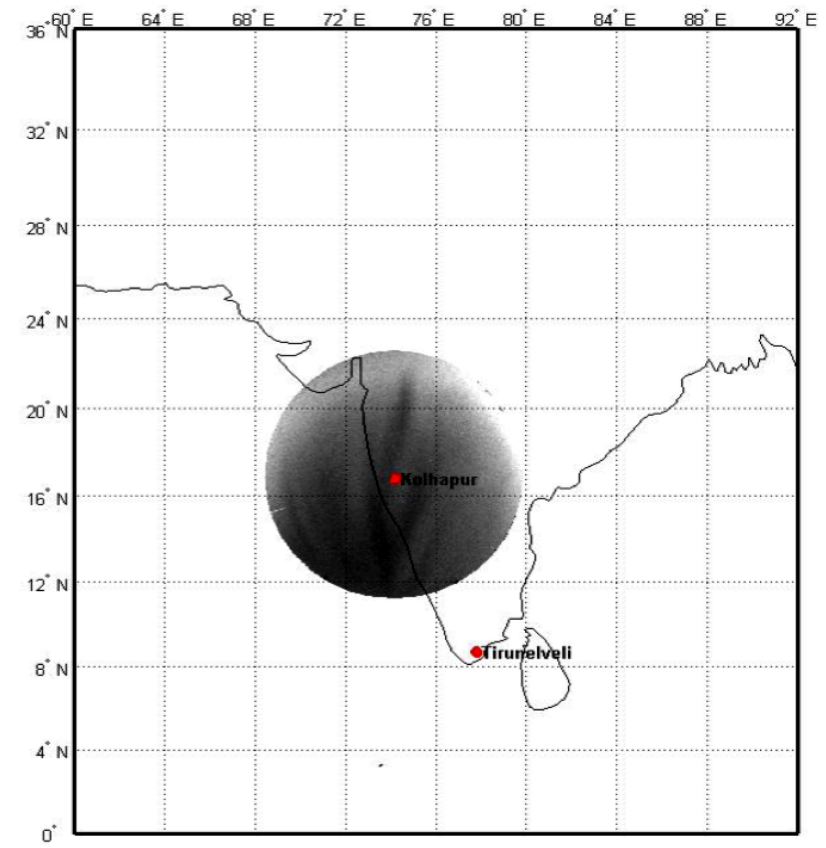

Figure 1. Locations of Kolhapur (all-sky imager) and Tirunelveli (ionosonde) station shown in the map by red dot. Circular shadow region show the field-of-view of all-sky imager (peak emission height of OI $630 \mathrm{~nm}$ at $\sim 250 \mathrm{~km}$ ).

vestigation, the Canadian advanced digital ionosonde was operated at 10-min temporal resolutions.

\section{Observation and data analysis}

We studies the characteristics of EPBs over Kolhapur, during the observation period of January to April 2012 using OI $630 \mathrm{~nm}$ airglow images. We compared the estimated plasma bubble drift velocity variations with the zonal wind estimates of HWM07 [Drob et al. 2008]. The locations of Kolhapur and Tirunelveli, from where imagining and ionosonde measurements were obtained respectively, are shown in Figure 1. A sample image is also projected indicating the region covered by FOV $140^{\circ}$ at $250 \mathrm{~km}$ altitude from where the OI $630 \mathrm{~nm}$ emission emanates.

Figure 2 illustrates typical structures in the F-region data recorded during this campaign. The dark bands in
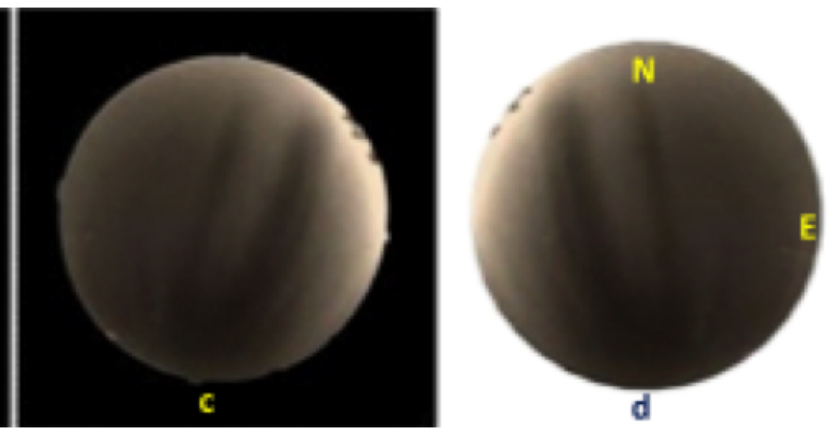
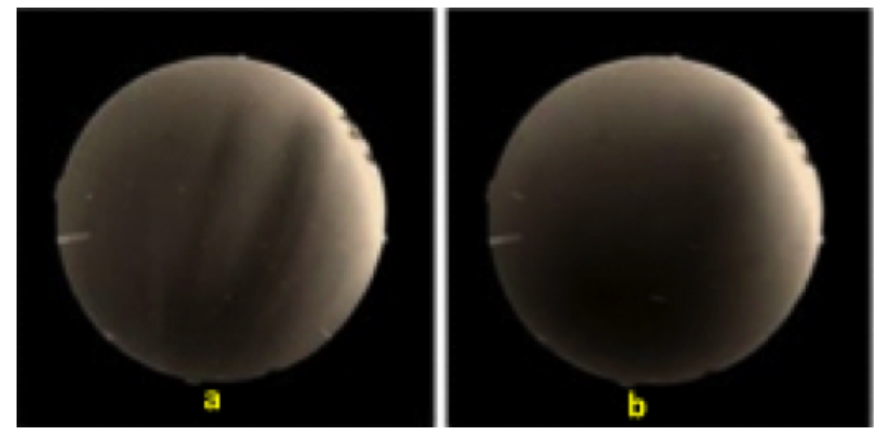

Figure 2. Sequence of image analysis (23-24 February 2012, on the image obtained at OI $630 \mathrm{~nm}$ emission at 1604 UT) carried out before the estimation of geophysical parameters. (a) Intensity adjusted image; (b) averaged image; (c) processed and star removed image; (d) spatially corrected image. 
the image depict magnetic north-south aligned F-region structures appearing as a series of depletions in the OI $630 \mathrm{~nm}$ airglow emission. Similar images have been used to study the morphology and dynamics of equatorial depletions observed from Kolhapur. All-sky image data of Kolhapur were collected at $\sim 6$-min interval for OI 630 $\mathrm{nm}$ emission. We have calculated the percentage of occurrence as the number of images on which at least one $\mathrm{EPB}$ is observed in one night divided by the total number of images recorded on that night.

Our image processing method is developed based on standard methods adapted for airglow image processing [Swenson and Mende 1994, Taylor and Garcia 1995, Mendillo et al. 1997]. The fisheye lens captures almost the entire night sky and projects the image on the CCD in such a way that each pixel subtends equal angle on the sky. Light from different parts of the sky are uniquely mapped to different parts of the CCD plane. Figure 2 illustrates the steps involved in preliminary image processing. Data show from the night of 23-24 February 2012 during the 1604 UT over Kolhapur. The OI $630 \mathrm{~nm}$ images were taken by all sky imager in PNG (portable network graphics) format shown in Figure 2a (adjusted brightness and contrast). Then we took the average of an hour OI $630 \mathrm{~nm}$ image-data which is shown in Figure 2b, and subtracted this averaged image from every image of hourly data which reduces the effect of steady background light. The stars were then removed from the image sequences using the standard deviation method.
We have taken local standard deviation of original image to detect stars in the image. The local standard deviation of image returns the new array of image, where each output pixel contains the standard deviation of the 3 by 3 neighborhood around the corresponding pixel in the input image which can have any dimension. We know the star position using the standard deviation method, once we detect the stars then enhance the image and then subtract image of star detected from original image to remove the stars. The simulation effect of the star removal is shown in Figure 2c [Patil et al. 2014]. After applying these processing steps we can easily distinguish the plasma bubble structure in OI $630 \mathrm{~nm}$ images which is shown in Figure 2c. After this processing, images were circular cropped, rotated by 70 in anti-clockwise direction and flipped horizontally for correct geographical alignment is shown in Figure 2d. The eastward zonal drift speeds of individual depletions were then determined by selecting two sequential images, with time steps of 6 minutes. Motion was measured at various positions along a given structure to determine its average velocity [Ghodpage et al. 2014, Taori and Sindhya 2014]. We calculated the EPB velocity for each image measurement and averaged theses estimates for 30 minutes, which are used further in the present study. This procedure was repeated for subsequent image pairs during the course of each night to determine the mean zonal drift speed of the plasma depletions as a function of time (Indian standard time $($ IST $)=$ Universal time $(\mathrm{UT})+$ 05:30 h).

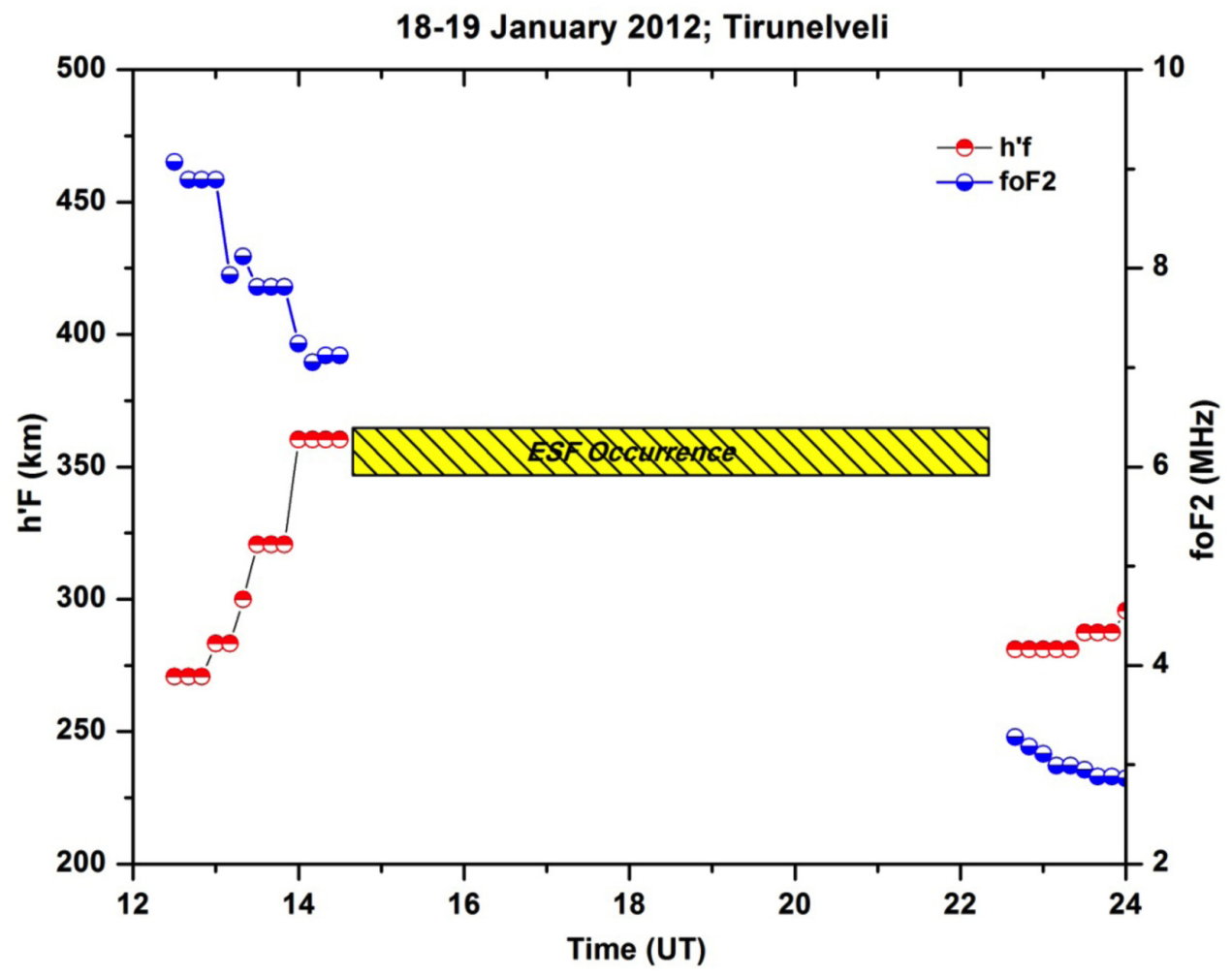

Figure 3. The ionosonde data corresponding to 18-19 January 2012. The time of ESF occurrence in ionosonde data are clearly mentioned. 


\subsection{Observation of $E P B$}

\section{and spread-F on 18-19 January 2012}

The occurrence and characteristic features of the EPBs noted in optical $\left(\mathrm{O}^{1} \mathrm{D}\right)$ night airglow and ionosonde data are as follows. The ionosonde data corresponding to 18 -19 January 2012 is shown over Tirunelveli $\left(8.71^{\circ} \mathrm{N}\right.$, $77.81^{\circ} \mathrm{E} ; 0.51^{\circ} \mathrm{N}$ dip latitude) in Figure 3 . The changes in h'F parameter provide a measure of vertical motions of the ionosphere. We noted that the F-layer height rose from $270.7 \mathrm{~km}$ to $360.3 \mathrm{~km}$ at the $1430 \mathrm{UT}$ (2000 IST) after which, spread-F was noted to persist till 2250 UT (0420 IST). Since the ionosonde is located at a dip equatorial station, the rise of the F-layer can be attributed only to the prereversal electric field enhancement. Meridional winds and diffusion do not play any role in raising the height of the $\mathrm{F}$ layer over the magnetic equator [Krishna Murthy et al. 1990].

During above mentioned observational period, optical data revealed the occurrence of EPBs. Figure 4 shows a time series of processed images of prominent $\mathrm{F}$ region structures recorded on 18-19 January 2012 at 1440 UT, 1532 UT, 1614 UT and 2103 UT. The ESF started at 1430 UT in ionosonde data and we have observed first plasma bubble on optical data at 1440 UT which is shows in Figure 4. We can see dark regions representing low airglow-intensity and were thus associated regions where electron density was depleted relative to the background. The north-south magnetic field-aligned EPB (dark structures) seen in the images are the optical signatures of the plasma bubbles or depletions. The image shows at 1532 UT three prominent plasma bubbles. The darkness of the EPBs starts decreasing from 2103 UT onwards, while moving towards the east. Table 1 shows the results of 53 nights of our observation. The direction of movement of depleted structures is indicated by the yellow arrow in Figure 4. The plasma bubble moves to the east as the time progresses. Drift velocities of individual depletions were then determined by selecting two sequential images, with time steps of $\sim 6$ minutes. Movement was measured at various positions along a given structure to determine its average velocity. It is clear from the images that the airglow intensity moved as a patch with no sharp gradient in the intensity within the patch and that the airglow intensity within the depletion is much less than the background intensity. As far as the determination of EPB velocity is concerned, we have taken the centre of the depletion structure as the reference. It is observed that the velocity of EPB is enhanced during the evening time and after it tends to decrease with increasing local time. After the local midnight, the eastward zonal drift velocities decrease steadily. Further, to see the time development of the depletions, we average the intensity values in 5 by 5 zenith pixel grid. The result of this analysis is shown in Figure 5. Over Kolhapur we observed that OI $630 \mathrm{~nm}$ intensity variations are characterized by four plasma depletions, passing over the ASAI at the 1549 UT, 1644 UT, 1739 UT and 1821 UT on 18-19 January which is shown as d1-d4 (Figure 5).
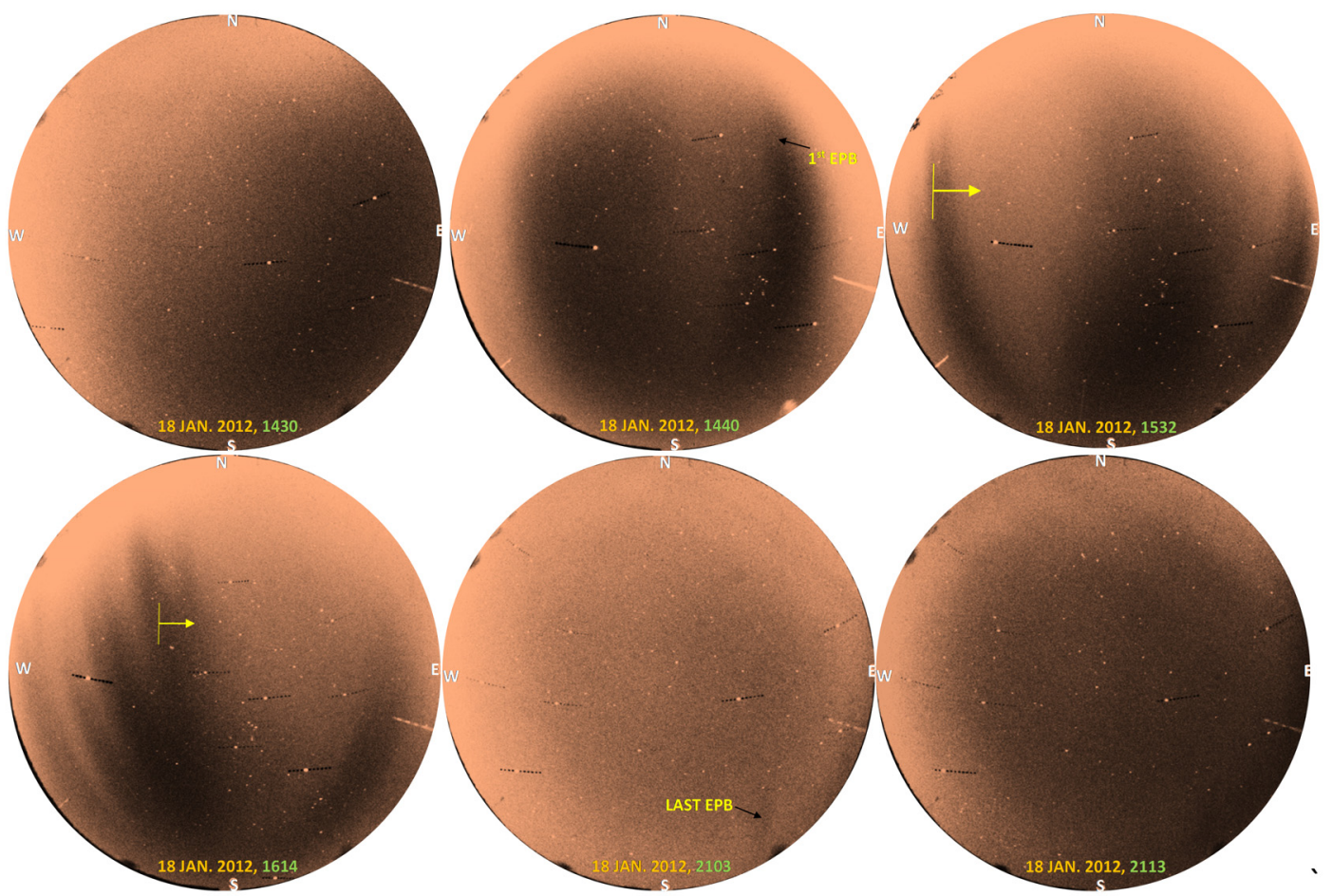

Figure 4. Sequence of images showing the occurrence of equatorial plasma bubble (EPB) and their movement from the west to the east direction on 18-19 January 2012. Movement of structures can be appearing in images (highlighted with yellow arrows). 
PATIL ET AL.

\begin{tabular}{|c|c|c|c|c|c|c|c|}
\hline $\begin{array}{l}\text { Sr. } \\
\text { No. }\end{array}$ & $\begin{array}{c}\text { Date } \\
\text { (Year: 2012) }\end{array}$ & $\begin{array}{c}\text { ESF } \\
\text { start time (UT) }\end{array}$ & $\begin{array}{c}\text { h'F height }(\mathrm{km}) \\
\text { at } 14 \mathrm{UT}\end{array}$ & $\begin{array}{c}\text { First EPB } \\
\text { obs. time (UT) }\end{array}$ & $\begin{array}{c}\text { Mean drift } \\
\text { velocity }(\mathrm{m} / \mathrm{s})\end{array}$ & $\begin{array}{l}\text { HWM velocity } \\
\text { estimates }(\mathrm{m} / \mathrm{s})\end{array}$ & $\begin{array}{c}\text { Total number } \\
\text { of images }\end{array}$ \\
\hline 1 & 17-18 Jan & $14: 30$ & 340 & $14: 30$ & $129 \pm 12$ & 106.5 & 113 \\
\hline 2 & 18-19 Jan & $14: 30$ & 320 & $14: 40$ & $145 \pm 16$ & 144.4 & 119 \\
\hline 3 & 19-20 Jan & $14: 10$ & 374 & $14: 25$ & $104 \pm 9$ & 163.1 & 111 \\
\hline 4 & 20-21 Jan & $13: 50$ & 387 & 14.30 & $145 \pm 13$ & 143.6 & 110 \\
\hline 5 & 21-22 Jan & $14: 10$ & 360 & $14: 30$ & $185 \pm 17$ & 154.8 & 105 \\
\hline 6 & 22-23 Jan & $16: 50$ & 310 & $14: 30$ & $225 \pm 21$ & 155.3 & 107 \\
\hline 7 & 23-24 Jan & $15: 50$ & 330 & $14: 30$ & $149 \pm 14$ & 146.3 & 158 \\
\hline 8 & 24-25 Jan & $14: 40$ & 320 & $15: 30$ & $194 \pm 18$ & 137.7 & 107 \\
\hline 9 & 25-26 Jan & No ESF & 295 & No EPB & - & - & 114 \\
\hline 10 & 26-27 Jan & 14:10 & 315 & $14: 30$ & $230 \pm 21$ & 147.2 & 124 \\
\hline 11 & 27-28 Jan & $14: 50$ & 325 & $15: 30$ & $179 \pm 17$ & 160.1 & 113 \\
\hline 12 & 28-29 Jan & $15: 50$ & 332 & $17: 30$ & $102 \pm 8$ & 87.4 & 92 \\
\hline 13 & 29-30 Jan & $14: 30$ & 322 & $16: 30$ & $119 \pm 11$ & 82.8 & 98 \\
\hline 14 & 30-31 Jan & $15: 40$ & 318. & $17: 10$ & $99 \pm 10$ & 85.9 & 82 \\
\hline 15 & 13-14 Feb & $13: 50$ & 350 & $14: 30$ & $191 \pm 18$ & 162.4 & 78 \\
\hline 16 & 14-15 Feb & $15: 00$ & 343 & $15: 30$ & $130 \pm 12$ & 151.3 & 76 \\
\hline 17 & $15-16 \mathrm{Feb}$ & $13: 30$ & 337 & $14: 30$ & $158 \pm 15$ & 144.6 & 105 \\
\hline 18 & 16-17 Feb & $13: 40$ & 316 & No EPB & - & - & 98 \\
\hline 19 & 17-18 Feb & $13: 30$ & 305 & $15: 30$ & $172 \pm 16$ & 107.1 & 104 \\
\hline 20 & 18-19 Feb & $14: 30$ & 343 & $16: 30$ & $180 \pm 17$ & 166.2 & 97 \\
\hline 21 & 20-21 Feb & $14: 00$ & 383 & $14: 30$ & $166 \pm 15$ & 136.8 & 107 \\
\hline 22 & $21-22 \mathrm{Feb}$ & $15: 10$ & 324 & 14:30 & $213 \pm 20$ & 162.4 & 115 \\
\hline 23 & 22-23 Feb & No ESF & 277 & No EPB & - & - & 122 \\
\hline 24 & 23-24 Feb & $14: 20$ & 372 & $14: 45$ & $157 \pm 14$ & 129.7 & 282 \\
\hline 25 & 24-25 Feb & $14: 00$ & 366 & $14: 40$ & $144 \pm 13$ & 129.9 & 155 \\
\hline 26 & 25-26 Feb & $14: 00$ & 383 & $14: 30$ & $144 \pm 13$ & 128.8 & 149 \\
\hline 27 & 26-27 Feb & $14: 40$ & 343 & $15: 30$ & $92 \pm 8$ & 70.1 & 144 \\
\hline 28 & 27-28 Feb & $14: 20$ & 373 & $14: 30$ & $146 \pm 13$ & 127.8 & 180 \\
\hline 29 & 28-29 Feb & $13: 50$ & 368 & $15: 30$ & $168 \pm 16$ & 145.6 & 128 \\
\hline 30 & 14-15 Mar & No ESF & 285 & No EPB & - & -- & 105 \\
\hline 31 & 16-17 Mar & No ESF & 295 & No EPB & - & - & 108 \\
\hline 32 & 17-18 Mar & $14: 00$ & 310 & $14: 30$ & $148 \pm 14$ & 143.1 & 113 \\
\hline 33 & 18-19 Mar & $14: 10$ & 308 & $15: 25$ & $136 \pm 12$ & 127.5 & 119 \\
\hline 34 & 19-20 Mar & $14: 20$ & 358 & $14: 31$ & $123 \pm 11$ & 112.7 & 105 \\
\hline 35 & 20-21 Mar & $13: 40$ & 301 & No Data & - & & 0 \\
\hline 36 & 21-22 Mar & $14: 20$ & 366 & $14: 17$ & $134 \pm 12$ & 106.1 & 126 \\
\hline 37 & 22-23 Mar & $13: 50$ & 395 & $14: 27$ & $136 \pm 12$ & 144.1 & 62 \\
\hline 38 & 23-24 Mar & $13: 50$ & 343 & $14: 38$ & $160 \pm 19$ & 146.5 & 137 \\
\hline 39 & 24-25 Mar & $14: 00$ & 351 & $15: 43$ & $181 \pm 17$ & 119.5 & 84 \\
\hline 40 & 25-26 Mar & $13: 50$ & 360 & $14: 30$ & $143 \pm 11$ & 124.8 & 110 \\
\hline 41 & 26-27 Mar & 14:30 & 343 & 15:00 & $159 \pm 15$ & 116.5 & 112 \\
\hline 42 & 12-13 Apr & No ESF & 289 & No EPB & - & & 68 \\
\hline 43 & 13-14 Apr & $16: 20$ & 318 & 19:09 & $73 \pm 10$ & 60.2 & 88 \\
\hline 44 & 14-15 Apr & $14: 50$ & 291 & No EPB & - & - & 96 \\
\hline 45 & 15-16 Apr & $13: 50$ & 285 & No EPB & - & - & 126 \\
\hline 46 & 16-17 Apr & $14: 30$ & 361 & $15: 46$ & $170 \pm 16$ & 140.8 & 88 \\
\hline 47 & 17-18 Apr & $14: 30$ & 292 & No EPB & - & - & 108 \\
\hline 48 & 18-19 Apr & No ESF & 305 & No EPB & - & - & 45 \\
\hline 49 & 21-22 Apr & $13: 50$ & 347 & $14: 40$ & $123 \pm 11$ & 116.9 & 110 \\
\hline 50 & 22-23 Apr & $14: 10$ & 323 & $15: 50$ & $142 \pm 13$ & 136.2 & 106 \\
\hline 51 & 23-24 Apr & 14:40 & 326 & $16: 30$ & $125 \pm 11$ & 110.4 & 104 \\
\hline 52 & 24-25 Apr & No ESF & 289 & No EPB & - & - & 108 \\
\hline 53 & 25-26 Apr & No ESF & 300 & No EPB & - & - & 109 \\
\hline
\end{tabular}

Table 1. Result of night airglow observation during the period of January to April 2012. 


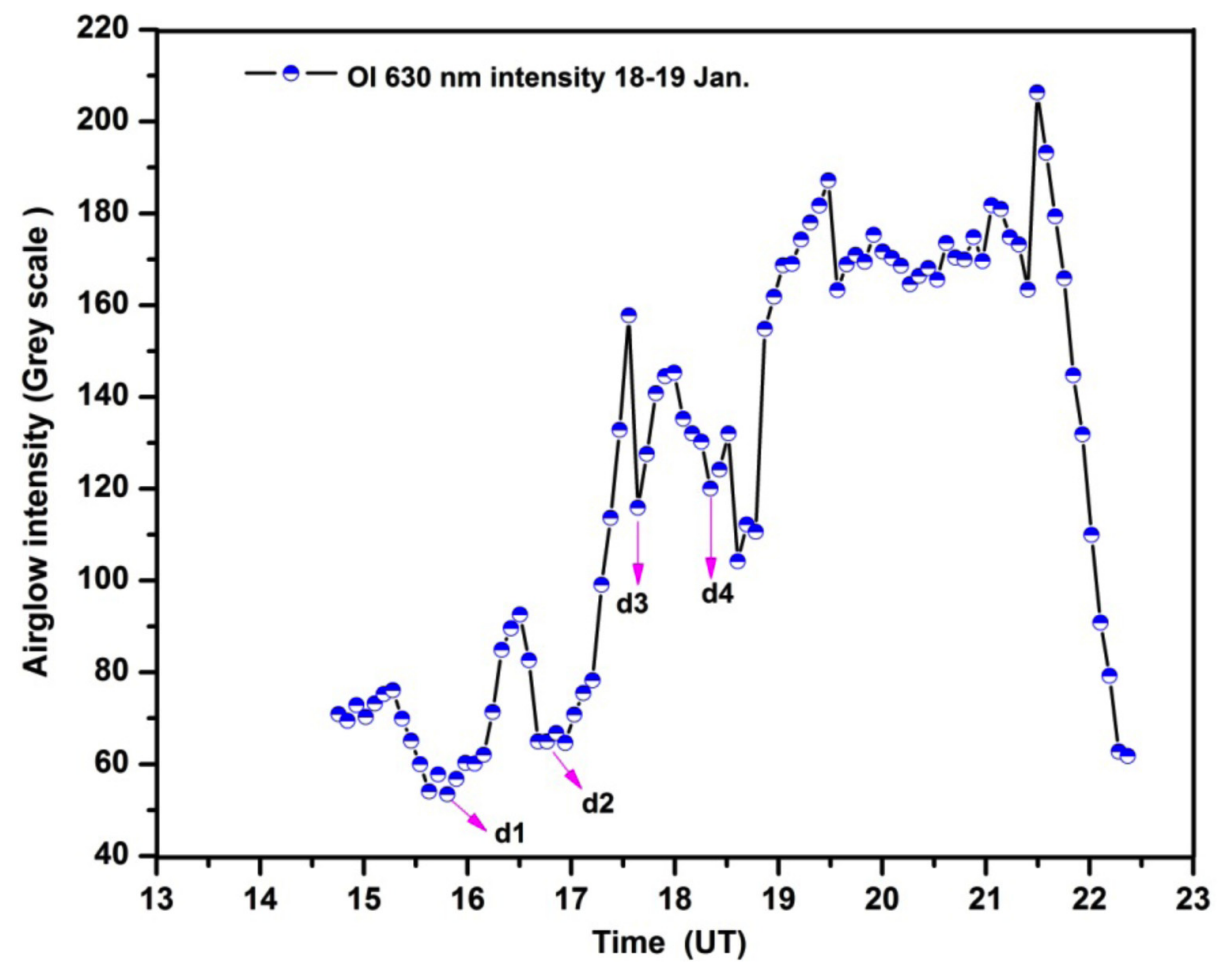

Figure 5. Sample zenith intensity plot for the observations corresponds to 18-19 January presenting the occurrence of depletion events.

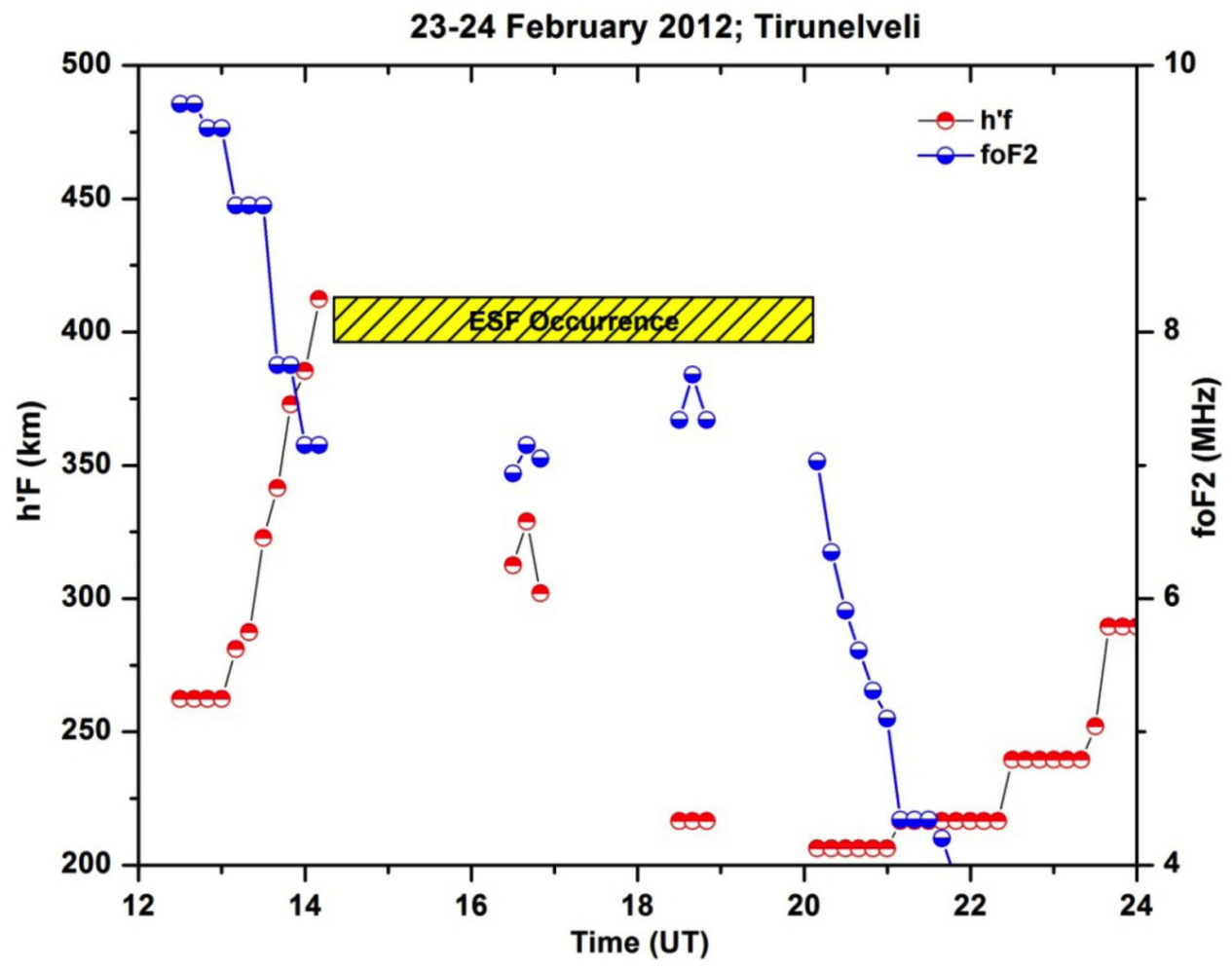

Figure 6. Same as Figure 3, but on 23-24 February 2012.

\subsection{Observations of $E P B$}

and spread-F on 23-24 February 2012

Another example of ESF observed in ionosonde data on 23-24 February 2012. The h'F altitude moved up to $435.2 \mathrm{~km}$ before the occurrence of ESF (Figure 6). After $\sim 1420$ UT (1950 IST), strong ESF was noted in the ionosonde data. Some of the images corresponding to
23-24 February 2012 are shown in Figure 7. ASAI camera show first EPB structure on 1445 UT and ESF was initiated on 1420 UT. Multiple EPB structures were observed over the next $\sim 8 \mathrm{~h}$ upto morning. We have noted eastward movements within two small time intervals of 1652 UT to 1714 UT. On 1944 UT the last EPB was seen and after $\sim 2000$ UT there where no sig- 


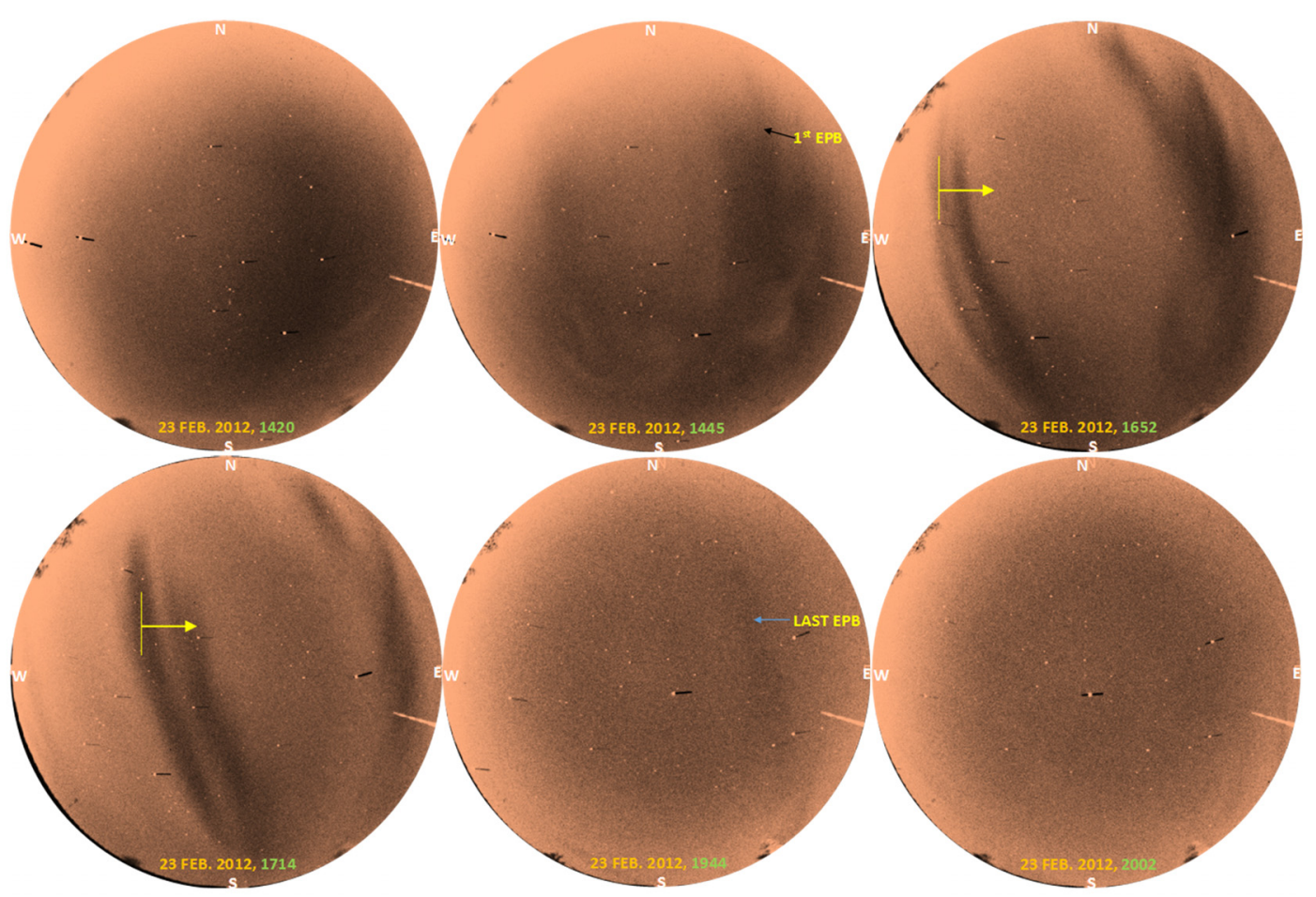

Figure 7. Same as Figure 4, but on 23-24 February 2012.

natures of EPB were observed. In order to determine the drift velocity of the plasma bubbles we scanned several images from east to west through the zenith after processing them we calculated the drift velocity of plasma bubble. We average the OI $630 \mathrm{~nm}$ intensity values in 5 by 5 zenith pixel grid. The results of this analysis is shown in Figure 8 for the period of 23-24 February 2012. Using this figure we can see that OI $630 \mathrm{~nm}$ in- tensity variations are characterized six depletions (d1d6) (Figure 8), extending at the 1430 UT, 1542 UT, 1606 UT, 1655 UT, 1740 UT and 1813 UT.

\section{Results and discussion}

Here we have used high-resolution airglow image data as elaborated in the previous section to investigate characteristics of the plasma depletions observed over

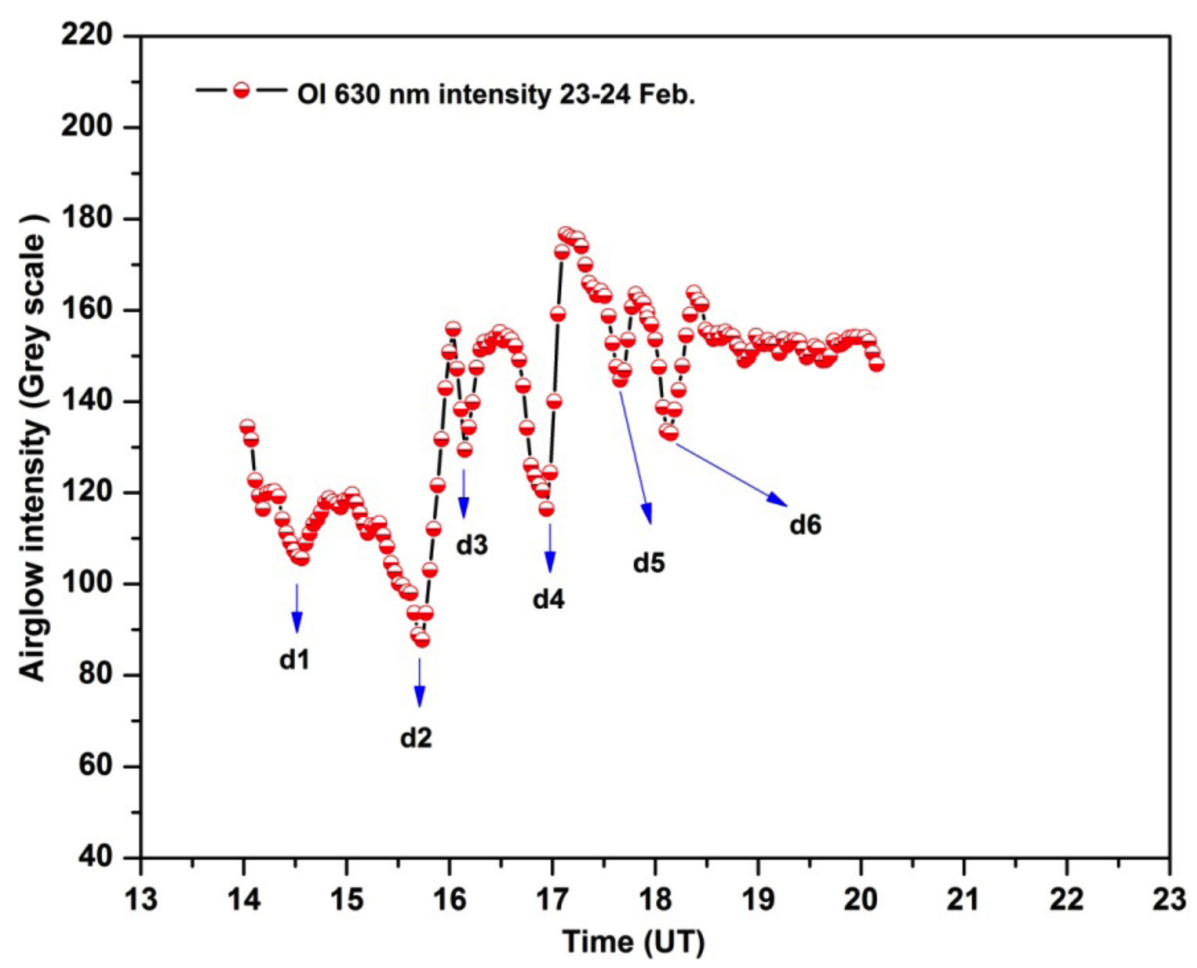

Figure 8. Sample zenith intensity plot for the observations corresponds to 23-24 February 2012, exhibiting the occurrence of depletion events. 

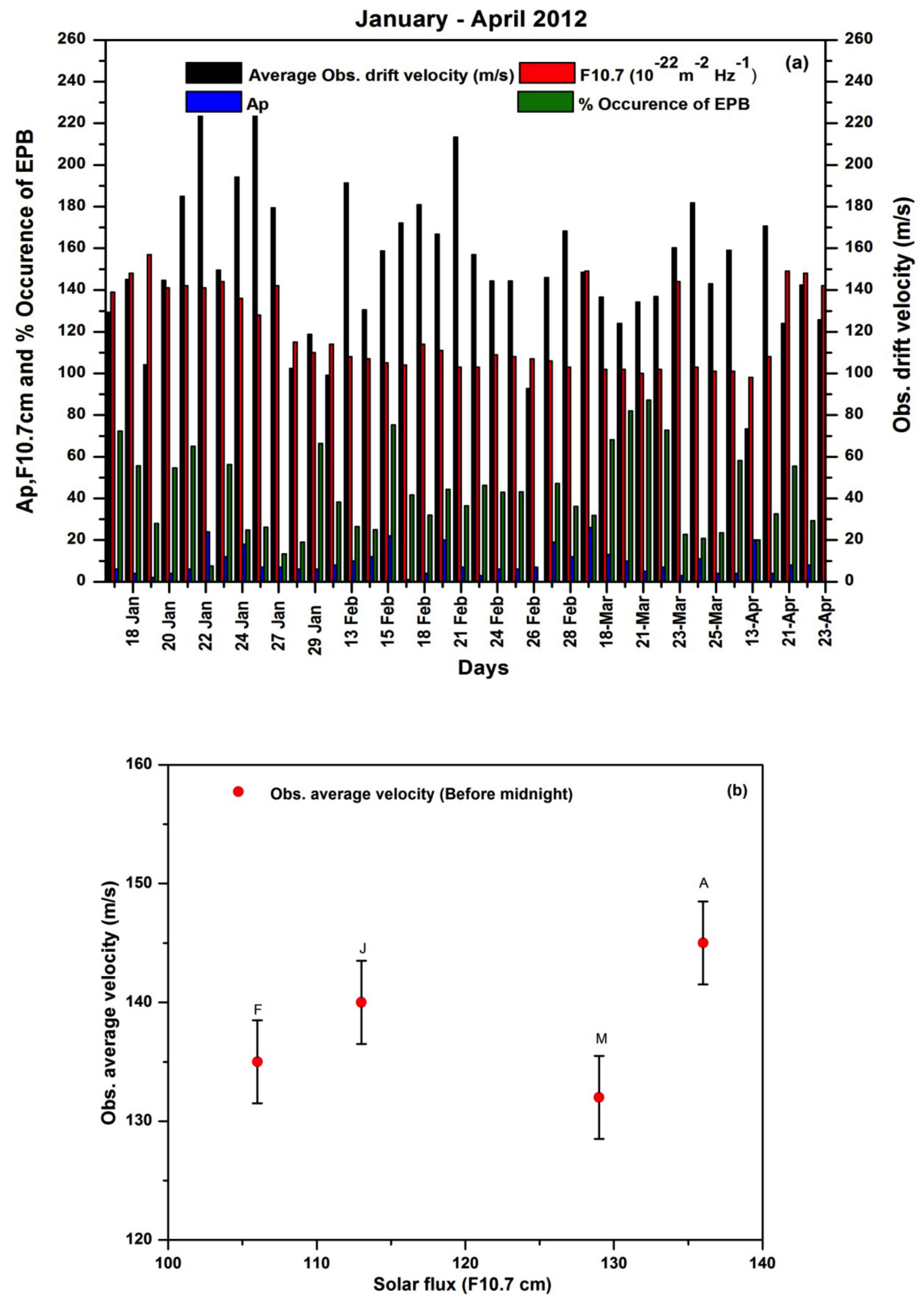

Figure 9 (this and the next page). (a) Variation between solar activity index Ap, $\mathrm{F}_{10.7} \mathrm{~cm}$, observed drift velocity and percentage of occurrence of plasma bubble during January-April 2012. (b) Variation of pre midnight monthly average drifts against the $\mathrm{F}_{10.7} \mathrm{~cm}$ solar flux values. The error bars show the variability in the estimated drift velocity and text J, F, M and A represented January, February, March and April 2012, respectively. Error bar is shown the standered deviation. (c) Variation of pre midnight monthly average drifts against the average Ap index values. The error bars show the variability in the estimated drift velocity and text J, F, M and A represented January, February, March and April 2012. Error bar is shown the standered deviation. 


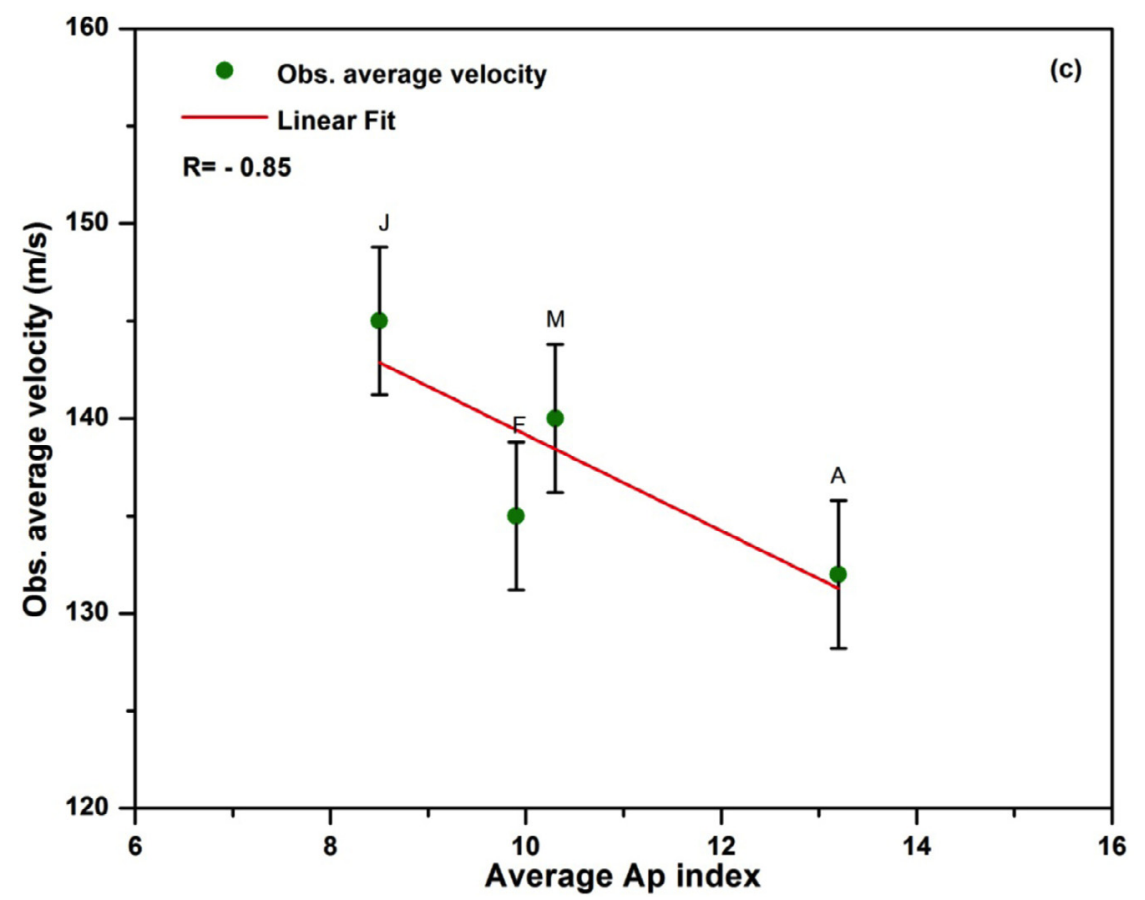

Figure 9c. See previous page.

(a) January 2012

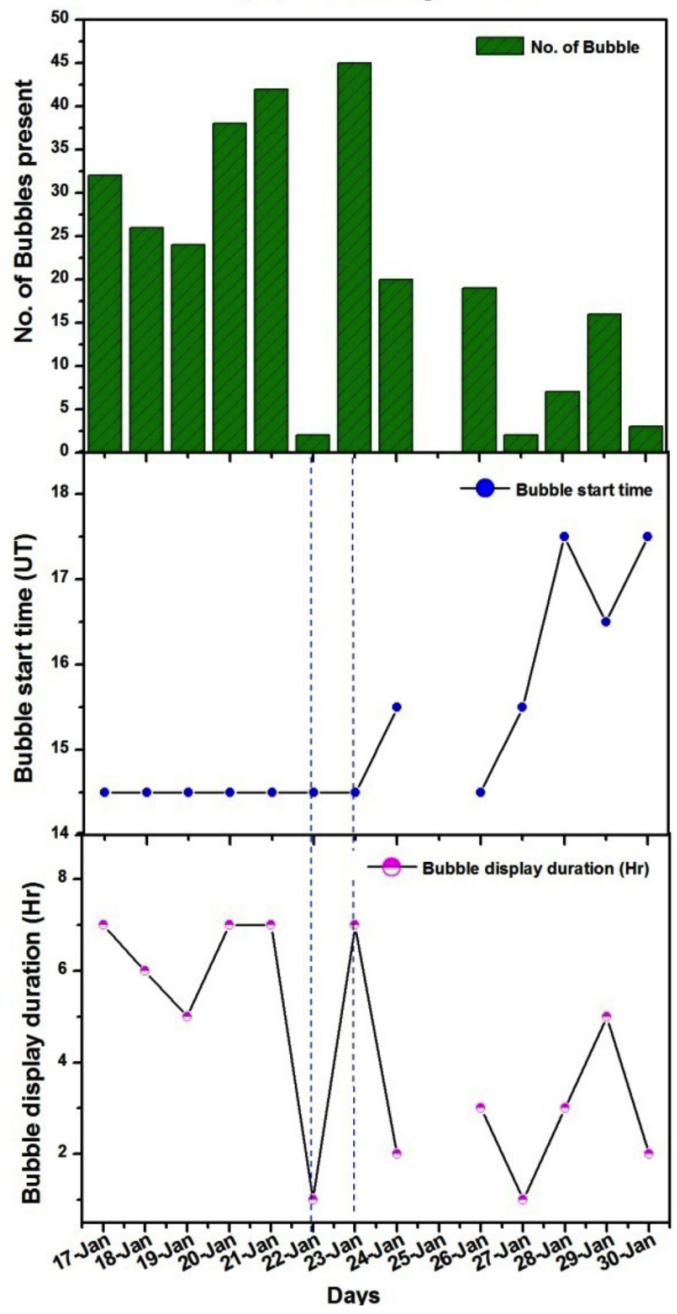

(b) February 2012

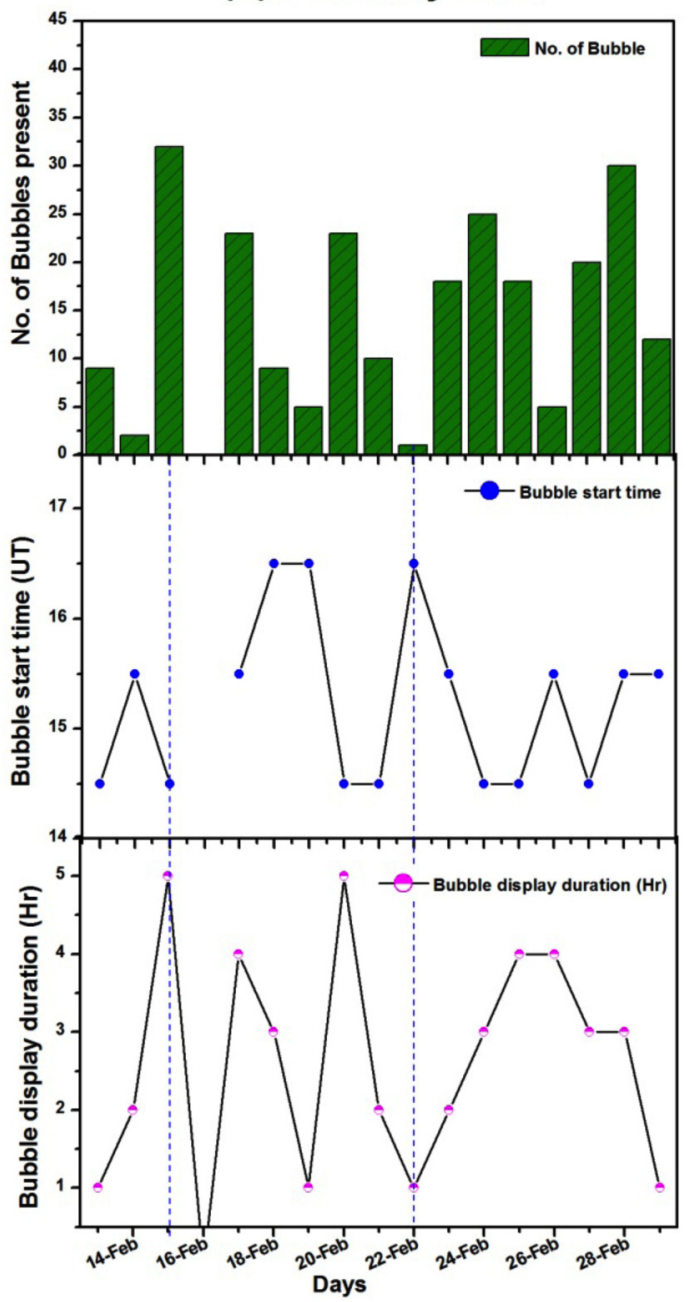

Figure 10. (a) Top panel depicted the total number of depletion structures observed each night, middle panel represented the onset time of the depletions for January 2012 over Kolhapur, and (bottom) their nocturnal duration (EPB observed durations). (b) Same as (a), but on February 2012. (c), (d) See next page. 
low latitude region. We have used the OI $630 \mathrm{~nm}$ emission night airglow image data collected from January to April 2012. From above said period, total 53 nights of clear sky observations with more than 9 hours of data on each night. Among these, 40 nights showed the occurrence of EPBs which are used in the present study.

\subsection{Percentage occurrence of $E P B$}

We summarize the image measurements of OI $630 \mathrm{~nm}$ night airglow emission during January to April 2012 in Table 1. In the Indian region, the occurrence of plasma irregularities has been studied by several investigators using ionosonde [Chandra et al. 2003], total electron content [Dashora et al. 2012] and VHF/UHF band scintillations [Das Gupta et al. 1981, Chakraborty et al. 1999], however, using optical data there have been limited investigations [Narayanan et al. 2012, Taori and Sindhya 2014]. In the recent study of Sharma et al. [2013] have shown the occurrence characteristics, however, we re-look into this aspect during a specific year

\section{(c) March 2012}

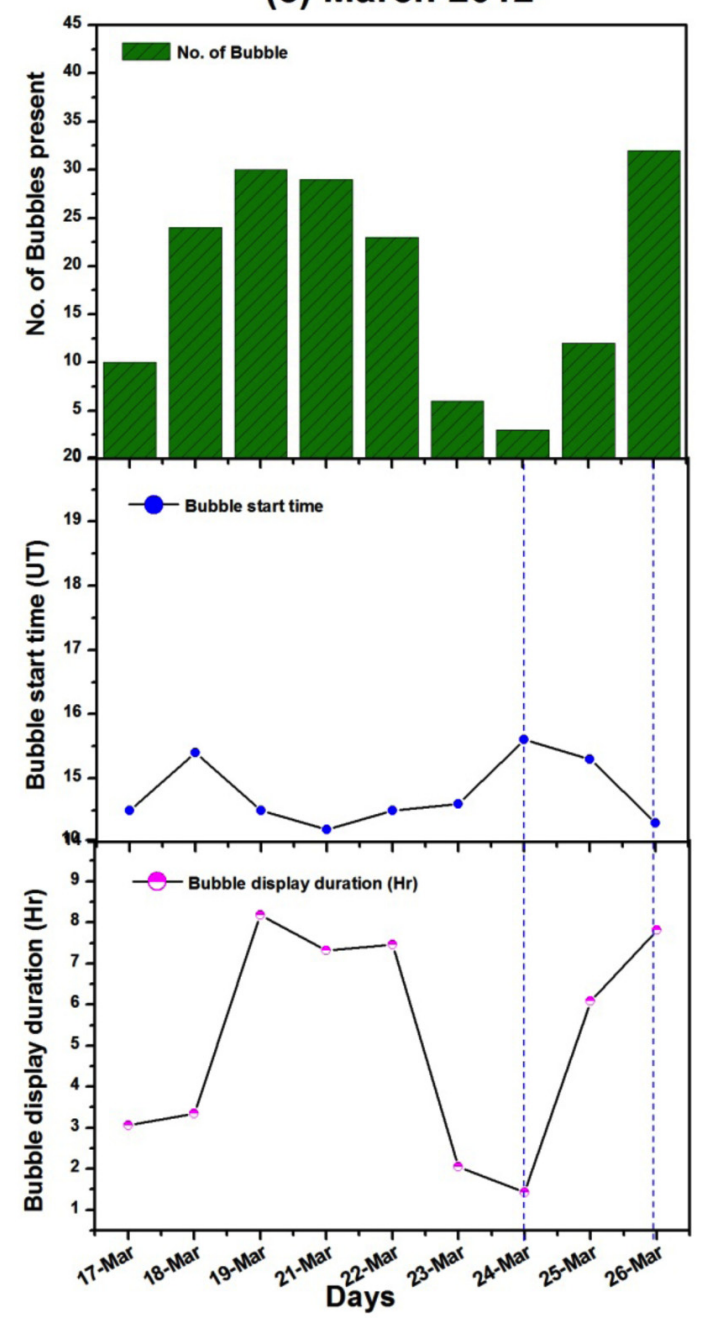

2012 with ionospheric parameters. We have examined the night-to-night variations of drift velocity, solar activity and geomagnetic activity which is shown in Figure 9a during January to April 2012. Over this period, we could operate the airglow imager during 53 nights, out of which 40 nights showed the EPB signatures, suggesting that $75.4 \%$ the large scale ionospheric irregularities were present. We further estimate the intensity of the EPB event as the number of images on which at least one EPB is observed in one night divided by the total number of images recorded by same night. In Figure 9a, black bars indicate average observed drift velocity; red and blue bars indicate solar flux $\left(\mathrm{F}_{10.7} \mathrm{~cm}\right)$ and Ap values respectively. Olive bar represents time variations in the percentage occurrence in the months from January to April. Among the 53 nights, 33 nights showed geomagnetic conditions were mostly quiet with Ap values $<15$. The $\mathrm{F}_{10.7} \mathrm{~cm}$ flux values varied from 98 to 157 ( 1 unit $=10^{-22} \mathrm{~m}^{-2} \mathrm{~Hz}^{-1}$ ). We observed maximum percentage occurrence of depletions $73.3 \%$,

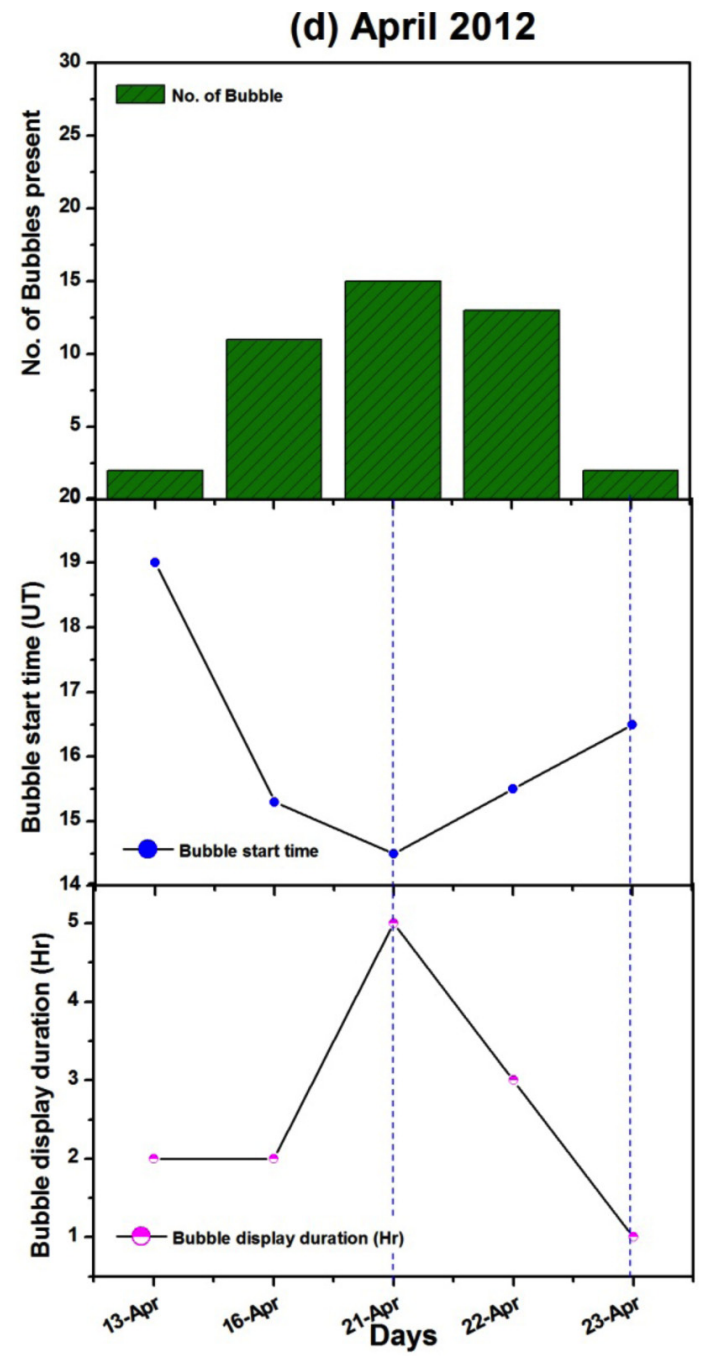

Figure 10 (continues from previous page). (c) Same as (a), but on March 2012. (d) Same as (a), but on April 2012. 
$65 \%$ and $66 \%$ and drift velocity $129 \mathrm{~ms}^{-1}, 185 \mathrm{~ms}^{-1}$ and $118 \mathrm{~ms}^{-1}$ during 17, 21 and 29 January 2012, respectively. Similarly, on 15, 23 and 27 February 2012, maximum percentage occurrence $75.3 \%, 46.2 \%$ and $47.2 \%$ and observed drift velocity were found to be $158 \mathrm{~ms}^{-1}, 157 \mathrm{~ms}^{-1}$ and $146 \mathrm{~ms}^{-1}$, magnetically quite time noted. We have found maximum percentage of occurrences on 19, 21 and 22 March 2012, which were $87 \%, 82 \%$ and $72 \%$ respectively. Corresponding days drift velocities vary between the $123-136 \mathrm{~ms}^{-1}$. In the month of April we observed maximum percentage occurrence of depletion (32\% and 55\%) on 16 and 21 April 2012.

In contrast to minimum percentage occurrence of depletion observed on 22 and 27 January 2012 was 7 and $13 \%$, respectively, as shown in Figure 9a. The Ap values were 24 and $7\left(\mathrm{~F}_{10.7} \mathrm{~cm}\right.$ were 141 and 142). The minimum percentage occurrence of EPB on 14 and 26 February 2012 were $25 \%$ and $20 \%$ respectively. The Ap values observed 12, 7 and the solar fluxes were varied 107 and 108 respectively. In March, we noted minimum percentage occurrence on 23 and 24 March 2012, which were $22 \%$ and $20 \%$ respectively. Along with $\mathrm{F}_{10.7} \mathrm{~cm}$ and Ap values were 144, 103 and 3, 11 respectively. Similarly, we have seen the minimum percentage occurrence on 13 and 23 April 2012. When the depletion starting time is earlier, then we observed more percentage occurrence of depletions, which are shown in Figure 10a,b,c,d. Here we observed that possibility of occurrence of EPBs increases rapidly after 1400 UT (1930 IST) and reaches a maximum value at about 1730 UT (2300 IST). Generally it is observed that the occurrence of EPB is very low during the months April-May, whereas it maximizes during the months October-March [Sharma et al. 2013]. In the Brazilian sector Abdu et al. $[1985,2003]$ reported the maximum occurrence of equatorial spread-F in period of October to March.

There are some reports indicating that pre-midnight drift velocities have a positive correlation with solar activity [Pimenta et al. 2001, Pimenta et al. 2003a, Fejer et al. 2005, Ghodpage et al. 2014, Taori and Sindhya 2014]. We attempt to see whether the solar activity affected the plasma drift velocity estimates in short duration of January-April 2012. For this, we averaged the drift velocities observed before the mid-night hours on every observed night of each month. The monthly average velocity values and the $\mathrm{F}_{10.7} \mathrm{~cm}$ fluxes were plotted which is shown in Figure $9 \mathrm{~b}$. We observed that there is a positive correlation between $\mathrm{F}_{10.7} \mathrm{~cm}$ and drift velocities. We see that four data points in Figure 9b, first data point represented average drift velocity for the month of February, second for January, third for March and four for April. Out of four except one data point of March 2012, when average Ap values were 10.3 and $F_{10.7}$ $\mathrm{cm}$ was 113 with average drift velocity $140 \mathrm{~m} \mathrm{~s}^{-1}$, other values follow a linear trend. The error bars indicate the standard deviations which show the variability of the data. This positive correlation shows that our data also reveal the drift velocity increases with solar activity. Such a relation is believed to be due to the dependency of zonal drifts on the ionospheric conductivity and F-region dynamo electric fields [Fejer et al. 2005, Siingh et al. 2005, Siingh et al. 2007] which are strongly affected by the solar flux. We note that there exist a negative correlation $(\mathrm{R}=-0.85)$ between the plasma bubble drift velocity and Ap values (Figure $9 \mathrm{c}$ ). This is consistent with the present understanding that during disturbance time the F-region dynamo electric fields are suppressed which results in a subdued drift velocities.

\subsection{EPB occurrence, onset and duration}

In Figure 10a,b,c,d, top panel plots show the number of plasma bubbles observed on each night during the observations. Prominent day-to-day variation in the total number of plasma bubbles is observable, which varied from 2 to 42 in January, 2 to 32 in February, 3 to 32 in March, and 2 to 15 in April. We have observed maximum 45 total numbers of EPB on 23 January, and 32 total numbers of EPB on 15 February, respectively. Similarly, 32 total numbers of EPB observed on 26 March. Maximum 15 numbers of EPBs observed on 23 April. In January we have observed seven nights with more than 20 numbers EPBs and two days less than 5 numbers EPBs. In February, we observed six nights with more than 20 numbers of EPBs with only one night showing less than 5 numbers of EPBs. In the month of March, five nights observed more than 20 numbers of EPBs and only one night exhibited less than 5 numbers of EPBs. Similarly, during the month of April we could see only two nights having less than 5 numbers of EPBs, but not even a single night with more than 20 numbers of EPBs.

In Figure 10a,b,c,d (middle) plots the initial onset time (observation time when EPB was first sighted in the image data) of the EPBs that were observed as they appear in the field of view of the all sky imager camera. During the observation period, on most of the nights the onset time of these plasma structures occurred in the early evening around 1430 UT to 1630 UT (2000 to 2200 IST). For a comparison, in Figure 10a,b,c,d, bottom plots have shown the total observed duration of the EPBs for each night. From these three plots we can see that total number of EPB structures observed was strongly influenced by their initial onset time and persistence. On 23 January 2012, the onset time was early around $1430 \mathrm{UT}$ and 45 numbers of EPBs structures were observed during the night which is indicated by 


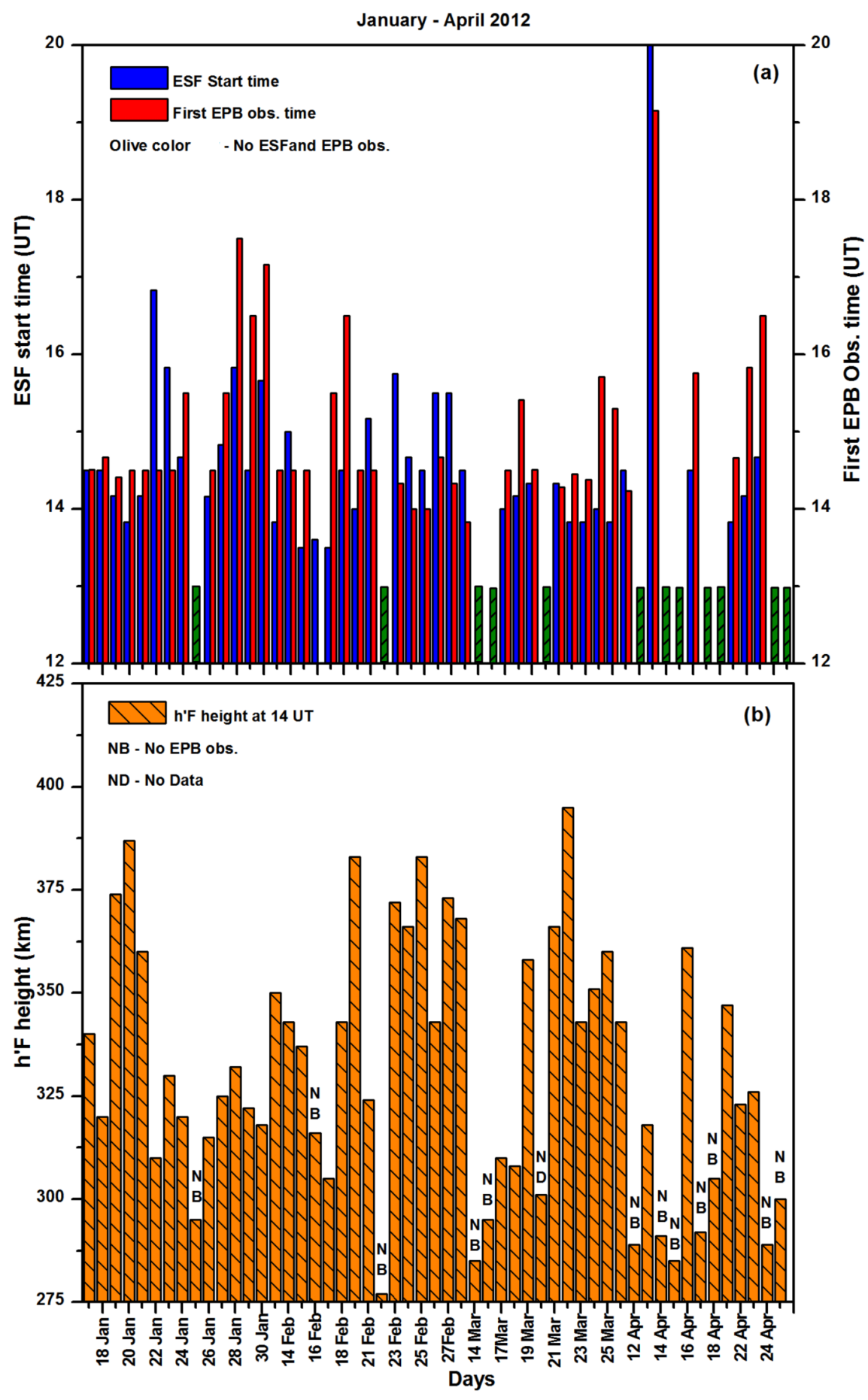

Figure 11. (a) Variation of the ESF starts time against the plasma bubble onset time of observed periods. Red color bar represent first plasma depletion observes time, blue bar show spred F start time and olive bar show ESF and EPB not observed on these perticualr days. (b) Day to day variation of h'F height in observed periods.

the dotted vertical line. Similarly, on 15 February 2012 the onset time was 1430 UT and 32 numbers of EPB structures were observed. On the other hand, during the nights of 22, 27 and 30 January 2012, when only a few numbers (2-4) EPBs were observed (indicated by the dotted lines), their onset time was 1-2 $\mathrm{h}$ late (after 1530 UT) and plasma structures persisted for a relatively short period of time, 1-3 h. Similarly, on the nights of 14, 19, 22 and 26 February 2012, a few (2-5 number) EPBs structure observed and their onset time was 1-2 $\mathrm{h}$ late and EPB persisted for relatively short duration, 1-2.5 h. Overall, we can say that the total number of EPBs was large when their onset time was early and their observed duration was long (5-7 h). Opposite to this, the total number of EPBs was less when their onset time was later (after 1530 UT) and EPBs observed for a short time. As the EPBs drift with the background, such a difference may arise because they may be generated in the western longitudes of Kolhapur and we observe them as they appear in the field of view. 


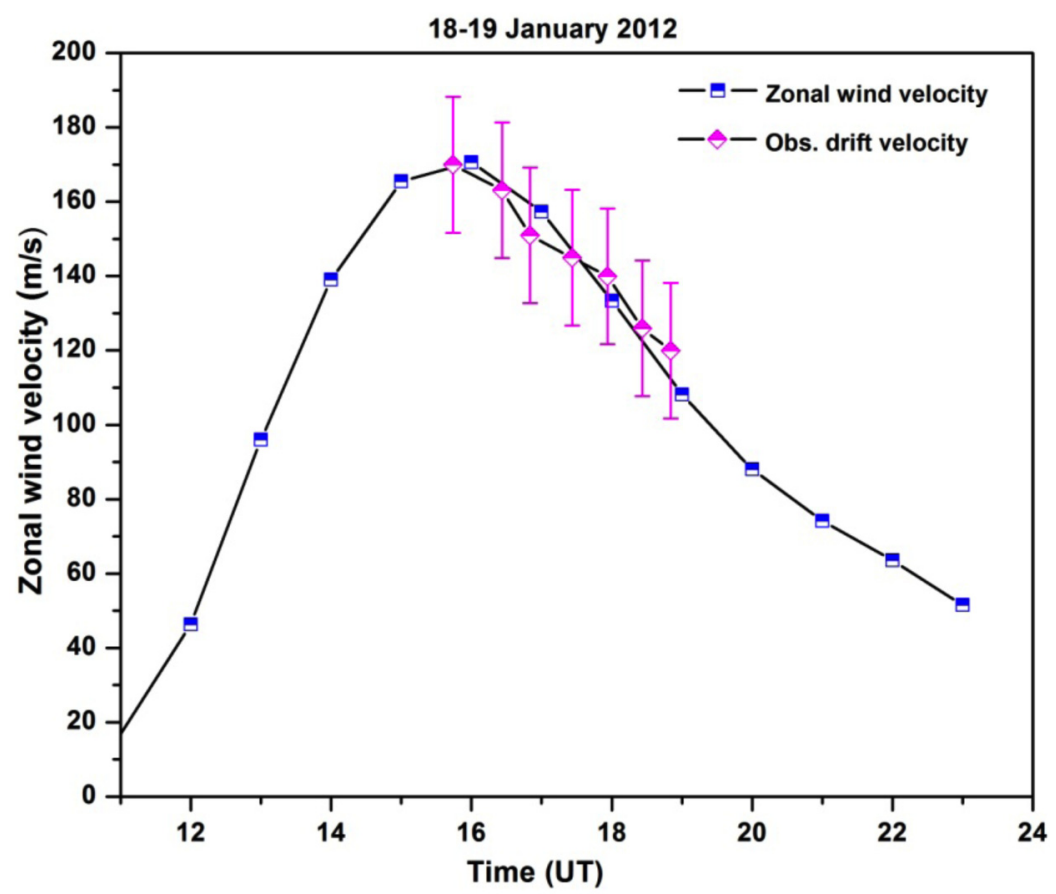

Figure 12. Comparison of observed EPB velocity with the zonal component of neutral wind velocity estimates by HWM07 on 18-19 January 2012 at Kolhapur (half filled pink diamond). Error bar show the standard deviation in each estimate.

\subsection{Relation between spread-F and occurrence of $E P B$}

The pre-conditioning of F-region before the occurrence of EPBs is evident in Figure 3 and 6, where the F-layer rising to higher altitudes is illustrated for the nights of 18-19 January and 23-24 February 2012. This is known to be associated with pre-reversal enhancement [Tsunoda 1985, Tsunoda 2005, Abdu et al. 2009, Narayanan et al. 2009]. The plots indicate the presence of ESF at the bottom side F-layer beginning as low as 260 to $270 \mathrm{~km}$ in most cases. It may be noted that the maximum height of the F-layer was more than $360 \mathrm{~km}$ on both the days. In Figure 6 after 1400 UT there was strong upward motion in the bottom side of F-layer which further led to the occurrence of plasma bubbles. The occurrence of EPBs were observed after 1440 and 1445 UT during the nights of 18-19 January and 23-24 February 2012 (Table 1).

Figure 11a shows the occurrence times of ESF in ionosonde data and EPBs in optical data. From this figure it is observed that most of the time EPBs are observed after a few minutes the occurrence of ESF in ionosonde data. Out of 53 nights, 40 nights exhibited the occurrence of north-south aligned EPB. On these $40 \mathrm{ob}-$ served days, most of time ESF was noticed in the ionograms first (all four types, viz., RSF, SSF, FSF, and MSF) of ESF have been noticed during the study period (we believe that investigation of different type of spread- $F$ may provide an in-depth analysis, however, with only 40 nights of data, it may not make a very meaningful statistics with respect to what we present in this report). The early appearance of ESF in the ionograms might be a limitation of optical data as they are operated only in clear night conditions with moonless conditions. Further, Since it is believed that ESF host the EPB irregularities, this observation indicates the fact that the ESF is first generated near the dip equator and later move to higher magnetic latitudes. To elaborate the importance of base height of F-layer on the occurrence of ESF, we noted the h'F values at $1400 \mathrm{UT}$ (Table 1). It is important to state that in most of the cases, whenever h'F values are higher than $300 \mathrm{~km}$, the ESF/EPB occurred. Day to day h'F variations were shown in Figure $11 \mathrm{~b}$.

The observed features may also be associated to the seeding mechanism of EPBs because the waves of different kind (gravity waves, LSWS, TIDs) may seed the Rayleigh-Taylor instability at a distant longitude sector as suggested by earlier investigators [Li et al. 2012]. Under favorable F-region conditions (as noted above), these seed perturbations may generate EPBs at different longitude sector and then drift to the location of observation (as discussed in Section 4.2).

\subsection{Comparison of observed EPB drifts velocities with} HWM07

From airglow images velocity and direction of the EPB structure were measured as a function of time. We have estimated the eastward drift velocities of the EPBs which are closely related to the nocturnal thermospheric zonal wind velocity. Also at night-time, ionospheric plasma drift velocities in the equatorial and low-latitude regions are approximately equal to the thermospheric zonal wind velocities [Rishbeth et al. 


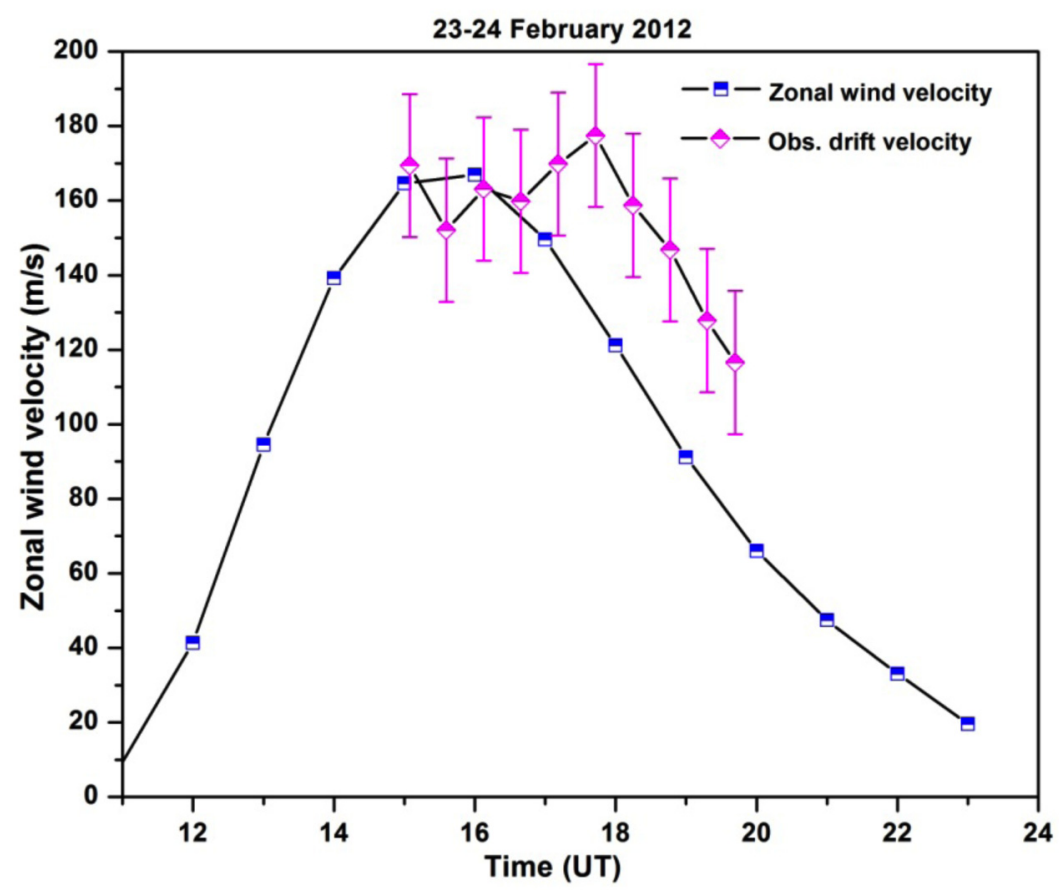

Figure 13. Same as Figure 12, but on 23-24 February 2012.

1972]. Further, the EPB drift velocities are believed to be equal to that of the ionospheric plasma drift velocities. At present, we do not have the zonal F-region wind measurements therefore, we compared the observed EPB drift velocities with the zonal component of neutral wind velocity computed using the HWM07 [Drob et al. 2008]. This model provides comprehensive statistical estimates based entirely on observational data. Inputs to the model include day of the year, local time, latitude, longitude, altitude, solar flux $\left(\mathrm{F}_{10.7} \mathrm{~cm}\right)$ and $\mathrm{Ap}$ value. The model output provides zonal and meridional winds for specified latitude, longitude. We used this model to see if it effectively reproduces the zonal ionospheric EPB drift velocities at low latitude. The model described is based on wind data obtained from the AE$E$ and $D E-2$ satellites. The first edition of the model was intended for winds above $220 \mathrm{~km}$. With the inclusion of wind data from ground based incoherent scatter radar and Fabry-Perot optical interferometers, this was extended down to $100 \mathrm{~km}$ and using MF/Meteor data, it was extended down to the ground [Hedin et al. 1996]. The improved version includes additional data from UARS/WINDII, HRDI measurements (Upper atmosphere research satellite/Wind imaging interferometer, High resolution doppler imager) and other measurements obtained from the NSF-CEDAR database (National Science Foundation - Coupling, Energetics and Dynamics of Atmospheric Regions). In the thermosphere, the model consists of two parts: a quiet-time period, and a geomagnetically disturbed period. The quiet-time represents average wind conditions when Ap value $\leq 12$. The disturbed part represents average per- turbation winds for the specified Ap input.

We plot the zonal component of the neutral wind velocities as a function of time computed using this HWM07 for 18-19 January 2012, shown in Figure 12. The calculated EPB velocity measurements are averaged for 30 minutes. Figure 12 reveals good agreement with the observed results and model estimates. The observed EPB drift velocity and model generated zonal component of the neutral wind velocities for 18-19 January 2012 were very well correlated to each other.

Similarly, on 23-24 February 2012, the estimated EPB drift velocity is shown in Figure 13. From the figure, the model calculated wind velocities were initially agreeing with the observations. However, after 1700 UT the observed values increased in magnitudes and were consistently higher by $20 \mathrm{~ms}^{-1}$ compared to the model outputs. Nevertheless, it is important to note that the trend of the variability predicted by the model is coinciding with the observations very well. The error bars in the observed values show the standard deviations representing the variability in the estimates. On this night, the EPB drift velocities increase till $\sim 1800$ UT (2330 IST) after which they steadily decrease till the early morning. The mean EPB drift velocities are noted to be $160 \pm 19 \mathrm{~ms}^{-1}, 158 \pm 14 \mathrm{~ms}^{-1}, 145 \pm 12 \mathrm{~ms}^{-1}$ and $127 \pm 13$ $\mathrm{ms}^{-1}$ during the months of January, February, March and April, respectively. The observed EPB drift velocities were higher than the model-predicted values by $20 \%$ during 1630-1830 UT (2200-2400 IST) and the differences were reduced as the night progressed. Sometime we noted differences between the observed EPB drift velocities and the zonal component of neutral winds 
could be explained due to the uncertainties in the assumed height of the emission layer during the period of observation. We observed that after 1800 UT (2330 IST), our observed velocity are larger than HWM07 estimated values. Usually, the differences between zonal component of neutral winds and EPB drift velocity in the post evening hours are because the F-region dynamo by that time is not fully activated [Chapagain et al. 2013, Taori and Sindhya 2014]. The EPBs drift with the background plasma while the winds are neutral phenomena occurring due to pressure gradient forces. A similarity in EPB velocity and neutral winds suggest a strong neutral-ion coupling. The deviations of EPB velocities from the neutral winds after the midnight are often suggested to be associated with the fact that after the midnight the EPBs are fossilized hence they tend to drift with the background plasma while, the neutral winds undergo a smooth variation by balancing the pressure gradients between day and night sector [Yao and Makela 2007, Taori and Sindhya 2014]. The EPB velocities and the model zonal wind velocities averaged for the duration of observed EPBs are listed in Table 1 emphasizing the differences.

Kishore and Mukherjee [2007] show the peak drift velocity in the range of 120 to $260 \mathrm{~ms}^{-1}$ over Indian low latitudes. There had been several reports of airglow imaging of plasma EPBs during geomagnetic quiet times [Sinha and Raizada 2000, Martinis et al. 2003, Pimenta et al. 2003b, Yao and Makela 2007, Chapagain et al. 2011]. The above investigators reported that large variations in the observed drift velocity in the range from $75 \mathrm{~ms}^{-1}$ to $185 \mathrm{~ms}^{-1}$. The climatological model of Fejer et al. [2005] reveals the zonal drifts velocity to vary from $100 \mathrm{~ms}^{-1}$ to $170 \mathrm{~ms}^{-1}$. Based on the optical imaging of OI $630 \mathrm{~nm}$ emission, Sinha and Raizada [2000] reported the peak drift velocities to be $195 \mathrm{~m} / \mathrm{s}$, while Taori and Sindhya [2014] reported the peak EPB drift velocity values are $120 \mathrm{~ms}^{-1}, 135 \mathrm{~ms}^{-1}, 160 \mathrm{~ms}^{-1}$, and $170 \mathrm{~ms}^{-1}$ during January, February, April and May 2013 at Gadanki $\left(13.5^{\circ} \mathrm{N}\right.$, $79.2^{\circ} \mathrm{E} ; 6.5^{\circ} \mathrm{N}$ dip latitude). Our measurements show the mean drift velocity vary between 125 to $160 \mathrm{~ms}^{-1}$ are therefore consistent with these reports. Future studies using multiple stations at closely spaced longitudinal observations such as those of currently being will provide crucial data for understanding longitudinal variability and the occurrence of EPB.

\section{Conclusions}

We have presented observations of nighttime airglow EPBs from Kolhapur using all-sky imager of the thermospheric OI $630 \mathrm{~nm}$ airglow emissions during January to April 2012. The magnetic field-aligned EPBs noted as EPBs are most likely associated with the de- velopment of ESF. In the most of the occasion it is observed that the appearance of EPBs in the FOV was observed during the evening time between 1400 to 1500 UT (1930-2030 IST). Average percentage occurrence of EPBs in the months from January to April 2012 varies in between $29-56 \%$. Further, we noted that positive correlation of occurrences with plasma drift velocity and solar flux, and somewhat negative correlation with the Ap values. We observed that the number of EPBs was well correlated with their initial onset time and their persistence. Measurements of EPB drift velocities from Kolhapur were eastward and exhibited significantly day-to-day variations in their magnitudes. The EPB drift velocity varies between $200-70 \mathrm{~ms}^{-1} \sim 2 \mathrm{~h}$ after the local sunset and it steadily decreases till dawn. Our measurements show the mean drift velocity $160 \pm 19$ $\mathrm{ms}^{-1}, 158 \pm 14 \mathrm{~ms}^{-1}, 145 \pm 12 \mathrm{~ms}^{-1} 127 \pm 13 \mathrm{~ms}^{-1}$ in January, February, March and April. The observed zonal EPB drift velocities and the zonal neutral wind velocities, obtained from the HWM07 empirical model, show similar patterns, indicating a strong thermosphere/ionosphere coupling at low latitudes, including the equatorial ionospheric anomaly region.

Acknowledgements. Indian Institute of Geomagnetism (IIG), Mumbai, is funded by the Ministry of Science and Technology, Government of India. We thank the Director of IIG, Navi Mumbai, for his encouragement to carry out this work. The night airglow observations at Kolhapur were carried out under the scientific collaboration programme (MoU) between IIG and Shivaji University, Kolhapur. Authors wish to thank the anonymous reviewers for their suggestions, which helped to improve the paper.

\section{References}

Abdu, M.A., J.H.A. Sobral, O.R. Nelson and I.S.Batista (1985). Solar cycle related range type spread-F occurrence characteristics over equatorial and low latitude station in Brazil, J. Atmos. Terr. Phys., 47, 901-905.

Abdu, M.A., I.S. Batista, H. Takahashi, J. MacDougall, J.H. Sobral, A.F. Medeiros and N.B. Trivedi (2003). Magnetospheric disturbance induced equatorial plasma bubble development and dynamics: A case study in Brazilian sector, J. Geophys. Res., 108 (A12), 1449; doi:10.1029/2002JA009721.

Abdu, M.A., I.S. Batista, B.W. Reinisch, J.R. de Souza, J.H.A. Sobral, T.R. Pedersen, A.F. Medeiros, N.J. Schuch, E.R. de Paula and K.M. Groves (2009). Conjugate Point Equatorial Experiment (COPEX) campaign in Brazil: Electrodynamics highlights on spread $\mathrm{F}$ development conditions and day-to-day variability, J. Geophys. Res, 114, 1-21, A04308; doi:10.1029/ 2008JA013749.

Arruda, D.C.S., J.H.A. Sobral, M.A. Abdu, V.M. Castilho, H. Takahashi, A.F. Medeiros and R.A. Buriti (2006). 
Theoretical and experimental zonal drift velocities of the ionospheric plasma bubbles over the Brazilian region, Adv. Space Res., 38, 2610-2614; doi:10.1016/ j.asr.2006.05.015.

Chakraborty, S.K., A. Das Gupta, S. Ray and S. Banerjee (1999). Long-term observation of VHF scintillation and total electron content near the crest of the equatorial anomaly in the Indian longitude zone, Radio Sci., 34, 241-255; http:// dx.doi.org/10.1029/ 98RS02576.

Chandra, H., S. Sharma, M.A. Abdu and I.S. Batista (2003). Spread-F at anomaly crest regions in the Indian and American longitudes, Adv. Space Res., 31, 717-727; http:/ / dx.doi.org/10.1016/S0273-1177(03) 00034-6.

Chapagain, N.P., M.J. Taylor and J.V. Eccles (2011). Airglow observations and modeling of $\mathrm{F}$ region $\mathrm{EPB}$ zonal velocities over Christmas Island, J. Geophys. Res., 116, A02301; doi:10.1029/2010JA015958.

Chapagain, N.P., D.J. Fisher, J.W. Meriwether, J.L. Chau and J.J. Makela (2013). Comparison of zonal neutral winds with equatorial plasma bubble and plasma drift velocities, J. Geophys. Res. Space Physics, 118, 1802-1812; doi:10.1002/jgra.50238.

Das Gupta, A., A. Maritra and S. Basu (1981). Occurrence of nighttime VHF scintillations near the equatorial anomaly crest in the Indian sector, Radio Sci., 16, 1455-1458; http:/ / dx.doi.org/10.1029/RS016i0 $06 \mathrm{p} 01455$.

Dashora, N., A. Taori and A.K. Patra (2012). Multi instrument observation of winter solstice F-region irregularities during the low solar activity, Ind. J. Radio Space Phys., 41, 220-232.

de Paula, E.R., I.J. Kantor, J.H.A. Sobral, H. Takahashi, D.C. Santana, D. Gobbi, A.F. Medeiros, L.A.T. Limiro, H. Kil, P.M. Kintner and M.J. Taylor (2002). Ionospheric irregularity zonal velocities over Cachoeira Paulista, J. Atmos. Sol-Terr. Phy., 64, 1511-1516; doi:10.1016/S1364-6826(02)00088-3.

Drob, D.P., J.T. Emmert, G. Crowley, J.M. Picone, G.G. Shepherd, W. Skinner, P. Hays, R.J. Niciejewski, M. Larsen, C.Y. She, J. Meriwether, G. Hernandez, M.J. Jarvis, D.P. Sipler, C.A.Tepley, M.S. O’Brien, J.R. Bowman, Y. Murayama, S. Kawamura, I.M Reid and R.A. Vincent (2008). An empirical model of the Earth's horizontal wind fields: HWM07, J. Geophys. Res., 113, 1-18; http:// dx.doi.org/10.1029/2008JA 013668.

Fejer, B.G., E.R. de Paula, S.A. Gonzalez and R.F. Woodman (1991). Average vertical and zonal F region plasma drifts over Jicamarca, J. Geophys. Res., 96 (A8), 13901-13906; doi:10.1029/91JA01171.

Fejer, B.G., J.R. Souza, A.S. Santos and A.E. Cost Pereira
(2005). Climatology of F region zonal plasma drifts over Jicamarca, J. Geophys. Res., 110, A12310; doi:10. 1029/2005JA011324.

Garcia, F.J., M.J. Taylor and M.C. Kelley (1997).Two-dimensional spectral analysis of mesospheric airglow image data, Appl. Opt., 36 (29), 7374-7385; doi:10.13 64/AO.36.007374.

Ghodpage, R.N., Devendraa Siingh, R.P. Singh, G.K. Mukherjeeand, P. Vohat and A.K. Singh (2012). Tidal and gravity waves study from ground based optical measurements at low latitude, Kolhapur (India), J. Earth Syst. Sci., 121 (6), 1511-1525; doi:10.1007/s120 40-012-0240-4.

Ghodpage, R.N., A. Taori, P.T. Patil, S. Gurubaran, S. Sripathi, S. Banola and A.K. Sharma (2014). Simultaneous optical measurements of equatorial plasma bubble (EPB) from Kolhapur $\left(16.81^{\circ} \mathrm{N}, 74.21^{\circ} \mathrm{E}\right)$ and Gadanki $\left(13.51^{\circ} \mathrm{N}, 79.21^{\circ} \mathrm{E}\right)$, J. Atmos. Terr. Phys., 121, 196-205; http:/ / dx.doi.org/10.1016/j.jas tp.2014.05.008i.

Ghodpage, R.N., A. Taori, P.T. Patil, S. Gurubaran, D. Siingh and A.K. Sharma (2015). On the vertical wavelength estimates using the Krassovsky parameters of OH airglow monitoring, Current Science, 108 (7), 1362-1369.

Grant, I.F., J.W. MacDougall, J.M. Ruohoniemi, W.A. Bristow, G.J. Sofko, J.A. Koehler, D. Danskin and D. Andre (1995). Comparison of plasma flow velocities determined by the ionosonde Doppler drift technique, Super DARN radars, and patch motion, Radio Sci. (USA), 30, 1537-1549.

Hanson, W.B., and S. Sanatani (1973). Large $N_{i}$ gradients below the equatorial F peak, J. Geophys. Res., $78,1167$.

Hedin, A., E.L. Fleming, A.H. Manson, F.J.Schmidlin, S.K. Avery, R.R. Clark, S.J. Franke, G.J. Fraser, T. Tsuda, F. Vial and R.A. Vincent (1996). Empirical wind model for the upper, middle and lower atmosphere, J. Atmos. Terr. Phys., 58, 1421-1447; doi:10.10 16/0021-9169(95)00122-0.

Kelly, M.C., G. Haerendel, H. Kappler, A. Valenzuela, B.B. Balsley, D.A. Carter, L. Ecklund, C.W. Carlson, B. Hausler and R. Torbert (1976). Evidence for a Rayleigh-Taylor-type instability and upwelling of depleted density regions during equatorial spread $\mathrm{F}$, Geophys. Res. Lett., 3, 448.

Kelley, M.C. (1989). The Earth's Ionosphere, Academic Press, CA, USA.

Kelley, M.C., J.J. Makela, B.M. Ledvina and P.M. Kintner (2002). Observations of equatorial spread $\mathrm{F}$ from Haleakala, Hawaii, Geophys. Res. Lett., 29 (20), 641 to 64-4; doi:10.1029/2002GL015509.

Kishore, M. Hari, and G.K. Mukherjee (2007). Equato- 
rial F-region plasma drifts: a study using OI $630 \mathrm{~nm}$ emission all-sky images, Current Science, 93 (4), 488-497.

Krishna Murthy, B.V., S.S. Hari and V.V. Somayajulu (1990). Nighttime equatorial thermospheric meridional winds from ionospheric h F data, J. Geophys. Res., 95, 4307-4310; doi:10.1029/JA095iA04p04307.

Li, G., B. Ning, M.A. Abdu, X. Yue, L. Liu, W. Wanand and L. Hu (2011). On the occurrence of post midnight equatorial $\mathrm{F}$ region irregularities during the June solstice, J. Geophys. Res., 116, A04318; doi:10.1029/ 2010JA016056.

Li, G., B. Ning, M. A. Abdu, W. Wanand and L. Hu (2012). Precursor signatures and evolution of postsunset equatorial spread-F observed over Sanya, J. Geophys. Res., 117, A08321; doi:10.1029/2012JA017 820.

Link, R., and L.L. Cogger (1989). A re-examination of the O I 6300-A nightglow, J. Geophys. Res., 93, 98839892, 1988; correction on J. Geophys. Res., 94, 1556.

Makela, J.J., B.M. Ledvina, M.C. Kelley and P.M. Kintner (2004). Analysis of the seasonal variations of equatorial plasma bubble occurrence observed from Haleakala, Hawaii, Annales Geophysicae, 22, 31093121; doi:10.5194/ angeo-22-3109-2004.

Martinis, C., J.V. Eccles, J. Baumgardner, J. Manzano and M. Mendillo (2003) Latitude dependence of zonal plasma drifts obtained from dual-site airglow observations, J. Geophys. Res. 108 (A3), 1129; http: / / dx.doi.org/10.1029/2002JA009462.

McClure, J.P., W.B. Hanson and J.H. Hoffman (1977) Plasma bubbles and irregularities in the equatorial ionosphere, J. Geophys. Res., 82, 2650.

Mendillo, M., J. Baumgardner, D. Nottingham, J. Aarons, B. Reinisch, J. Scali and M.C. Kelley (1997). Investigations of thermospherc ionospheric dynamics with $6300 \AA$ images from the Arecibo Observatory, J. Geophys. Res., 102, 7331-7343; dx.doi.org/10.10 29/96JA02786.

Morse, F.A., B.C. Edgar, H.C. Koons, C.J. Rice, W.H. Heikkila, J.H. Hoffman, B.A. Tinsley, J.D. Winningham, A.B. Christensen, R.F. Woodman, J. Pomalaza and N.R. Teixeira (1977). Equinox: An equatorial ionospheric irregularity experiment, J. Geophys. Res., 82, 578.

Mukherjee, G.K. (2003). Studies of equatorial F-region depletions and dynamics using multiple wavelength nightglow imaging, J. Atmos. Sol-Terr. Phy., 65, 379390; doi:10.1016/S1364-6826(02)00214-6.

Mukherjee, G.K., and D.J. Shetti (2008). Plasma drifts motion in F-region of ionosphere using photometric nightglow measurements, Indian J. Radio Space Phys., 37, 249-257.
Narayanan, V.L., S. Gurubaran and K. Emperumal (2009). Imaging observations of upper mesospheric nightglow emissions from Tirunelveli $\left(8.71^{\circ} \mathrm{N}\right)$, Indian J. Radio Space Phys., 38, 150-158.

Narayanan, V. Lakshmi, A.Taori, A.K. Patra, K. Emperumal and S. Gurubaran (2012). On the importance of wave-like structures in the occurrence of equatorial plasma bubbles: A case study, J. Geophys. Res., 117, A01306; doi:10.1029/2011JA017054.

Otsuka, Y., K. Shiokawa, M. Nishioka and Effendy (2012). VHF radar measurements of post-midnight F-region field-aligned irregularities over Indonesia during solar minimum, Ind. J. Radio Sp. Phys., 41, 199-207.

Patil, R.P., S.B. Patil, R.N. Ghodpage and P.T. Patil (2014). Star Detection and Removal in Night Airglow Images, IJIRSET., 14483-14488.

Patra, A.K., A. Taori, P.P. Chaitanyaand and S. Sripathi (2013). Direct detection of wavelike spatial structure at the bottom of the $F$ region and its role on the formation of equatorial plasma bubble, J. Geophys. Res. Space Physics, 118; doi:10.1002/jgra.50148.

Piggott, W.R., and K. Rawer (1972), U.R.S.I. handbook of ionogram interpretation and reduction, Report UAG 23A, World Data Center A for Solar-Terrestrial Physics, Boulder, CO, USA, 68-73.

Pimenta, A.A., P.R. Fagundes, J.A. Bittencourt, Y. Sahai, D. Gobbi, A.F. Medeiros, M.J. Taylor and H. Takahashi (2001). Ionospheric plasma bubble zonal drift: A methodology using OI (630.0 nm) all-sky imaging systems, Adv. Space Res., 27, 1219-1224; doi:10. 1016/S0273-1177(01)00201-0.

Pimenta, A.A., P.R. Fagundes, Y. Sahai, J.A. Bittencourt and J.R. Abalde (2003a). Equatorial F-region plasma depletion drifts: latitudinal and seasonal variations, Annales Geophysicae, 21, 2315-2322.

Pimenta, A.A., J.A. Bittencourt, Y. Sahai, R.A. Buriti, H. Takahashi and M.J. Taylor (2003b). Ionospheric plasma bubble zonal drifts over the tropical region: A study using OI (630.0 nm) emission all-sky images, J. Atmos. Sol-Terr. Phy., 65, 1117-1126; doi:10. 1016/S1364-6826 (03)00149-4.

Rao, P.B., A.K. Patra, T.V.C. Sharma, B.V. Krishnamurthy, K.S.V. Subbaraoand and S.S. Hari (1997). Radar observations of up drafting and down drafting plasma depletions associated with equatorial spread F, Radio Sci., 32, 1215-1227; doi:10.1029/97R S00094.

Rishbeth, H., P. Bauer and W.B. Hanson (1972). Molecular ions in the F2 layer, Planet. Space Sci., 20, 12871293.

Sagawa, E., T. Maruyama, T.J. Immel, H.U. Frey and S.B. Mende (2003). Global view of the nighttime low-lat- 
itude ionosphere by the IMAGE/ FUV $135.6 \mathrm{~nm}$ observations, Geophys. Res. Lett., 30 (10), 1534; doi:10. 1029/2003GL017140.

Sahai, Y., J.A. Bittencourt, N.R. Teixeiraand and H. Takahashi (1981). Simultaneous observations of OI 7774-A and OI 6300-A emissions and correlative study with ionospheric parameters, J. Geophys. Res., 86, 3657-3660.

Sahai, Y., P.R. Fagundes, F. Becker-Guedes, J.R. Abalde, G. Crowley, X. Pi, K. Igarashi, G.M. Amarante, A.A. Pimenta and J.A. Bittencourt (2004). Longitudinal difference observed in the ionospheric F-region during the major geomagnetic storm of 31 March 2001, Annales Geophysicae, 22 (9), 3221-3229.

Sharma, A.K, D.P. Nade, S.S. Nikte, P.T. Patil, R.N. Ghodpage, R.S. Vhatkar, M.V. Rokade and S. Gurubaran (2013). Occurrence of equatorial plasma bubbles over Kolhapur, Adv. Space Res., 54 (3), 435 442; http: / / dx.doi.org/10.1016/j.asr.2013.07.018

Sharma, A.K, D.P. Nade, S.S. Nikte, P.T. Patil, R.N. Ghodpage, R.S. Vhatkar, M.V. Rokade and S. Gurubaran (2014). Development of fast image analysis technique for All-Sky images, Current Science, 106 (8), 1085-1093

Shi, J.K. , G.J. Wang, B.W. Reinisch, S.P. Shang, X. Wang, G. Zherebotsov and A. Potekhin (2011). Relationship between strong range spread $\mathrm{F}$ and ionospheric scintillations observed in Hainan from 2003 to 2007, J. Geophys. Res., 116, A08306; doi:10.1029/2011JA 016806.

Siingh, D., R.P. Singh, A.K. Kamra, P.N. Gupta, R. Singh, V. Gopalakrishnan and A.K. Singh (2005). Review of electromagneticcoupling between the Earth's atmosphere and the space environment, J. Atmos. SolTerr. Phy., 67, 637-658; doi:10.1016/j.jastp.2004.09

Siingh, D., V. Gopalakrishnan, R.P. Singh, A.K. Kamra, S. Singh, V. Pant, R. Singh and A.K. Singh (2007). Theatmospheric global electric circuit: an overview, Atmos. Res., 84, 91-110; doi:10.1016/j.atmosres.2006. 05.005

Siingh, D., R.P. Singh, A.K. Singh, S. Kumar, M.N. Kulkarni and A.K. Singh (2012). Discharge in stratosphere and mesosphere, Space Sci. Rev., 169, 73-121; doi:10. 1007/s11214-012-9906-0.

Sinha, H.S.S., and S. Raizada (2000). Some new features of ionospheric plasma depletions over the Indian zone using all-sky optical imaging, Earth Planets Space, 52, 549-555.

Swenson, G.R., and S.B. Mende (1994). OH emission and gravity waves (including a breaking wave) in allimagery from Bear Lake, UT. Geophys. Res. Lett., 21, 2239-2242.

Taori, A., A. Jayaraman and V. Kamalakar (2013). Im- aging of mesosphere-thermosphere airglow emissions over Gadanki $\left(13.51^{\circ} \mathrm{N}, 79.21^{\circ} \mathrm{E}\right)$-first results, J. Atmos. Sol-Terr. Phy., 93, 21-28; http:// dx.doi. org/10.1016/j.jastp.2012.11.007.

Taori, A., and A. Sindhya (2014). Measurements of equatorial plasma depletion velocity using $630 \mathrm{~nm}$ airglow imaging over a low latitude Indian station, J. Geophys. Res. 119, 1-6; http:/ / dx.doi.org/10.1002/ 2013JA019465.

Taylor, M.J., and F.J.Garcia (1995). A two dimensional spectral analysis of short period gravity waves imaged in the $\mathrm{OI}(557.7 \mathrm{~nm})$ and near infrared $\mathrm{OH}$ nightglow emissions over Arecibo, Puerto Rico, Geophys. Res. Lett., 22, 2473-2476.

Taylor, M.J., J.V. Eccles, J. La Belleand and H.A. Sobral (1997). High resolution OI (630 nm) image measurements of F-region depletion drifts during the Guara campaign, Geophys. Res. Lett., 24, 1699-1702.

Tinsley, B.A., A.B. Christensen, J. Bittencourt, H. Gouveia, P.D. Angrejiand and H. Takahashi (1973). Excitation of oxygen permitted line emissions in the tropical nightglow, J. Geophys. Res., 78, 1174-1186.

Tsunoda, R.T. (1985). Control of the seasonal and longitudinal occurrence of equatorial scintillations by the longitudinal gradient in integrated $\mathrm{E}$ region Pedersen conductivity, J. Geophys. Res., 90 (A1), 447-456; doi:10.1029/JA090iA01p00447.

Tsunoda, R.T. (2005). On the enigma of day-to-day variability in equatorial spread F, Geophys. Res. Lett., 32, L08103; doi:10. 1029/2005GL022512.

Valladares, C.E., J.W. Meriwether, R. Sheehanand and M.A. Biondi (2002). Correlative study of neutral winds and scintillation drifts measured near the magnetic equator, J. Geophys. Res., 107 (A7), 1112; doi:10.1029/ 2001JA000042.

Woodman, R.F. (1972). East-west ionospheric drifts at the magnetic equator, Space Res., 81, 5447-5466.

Yao, D., and J.J. Makela (2007). Analysis of equatorial plasma bubble zonal drift velocities in the Pacific sector by imaging techniques, Annales Geophysicae, 25, 701-709; doi:10.5194/angeo-25-701-2007.

\footnotetext{
${ }^{\star}$ Corresponding author: Rupesh N. Ghodpage, MF Radar, Indian Institute of Geomagnetism, Shivaji University Campus, Kolhapur, Maharashtra, India; email: rupeshghodpage@gmail.com.

C 2016 by the Istituto Nazionale di Geofisica e Vulcanologia. All rights reserved.
} 